\title{
Time-dependent Probabilistic Tsunami Hazard Analysis for Western Sumatra, Indonesia, Using Space-Time Earthquake Rupture Modelling and Stochastic Source Scenarios
}

\author{
Ario Muhammad ${ }^{1,2}$, Katsuichiro Goda ${ }^{3}$, Maximilian J. Werner ${ }^{2}$ \\ $5 \quad{ }^{1}$ Civil Engineering Department, President University, Bekasi, 17530, Indonesia \\ ${ }^{2}$ School of Earth Sciences, University of Bristol, Bristol BS8 1TR, UK \\ ${ }^{3}$ Department of Earth Sciences, Western University, London, N6G 2V4, Canada \\ Correspondence to: Ario Muhammad (ario.muhammad@president.ac.id)
}

Abstract. We develop a novel framework of time-dependent probabilistic tsunami hazard analysis (PTHA) and apply it to

10 Western Sumatra, Indonesia, where future tsunamigenic events are anticipated in the Mentawai region of the Sunda subduction zone. An earthquake rupture model taking into account the spatiotemporal interaction of major megathrust segments is used to simulate future tsunamigenic earthquakes. The earthquake rupture process of the segments is characterized by a multivariate Bernoulli model with interarrival times following a Brownian passage-time distribution and the dependency between segments specified by a spatial correlation function. We calibrate this model with historical

15 ruptures of the Mentawai thrust in the last 450 years. A total of $\geq 100,000$ time-dependent earthquake rupture cases are then coupled with a stochastic tsunami simulation method to evaluate tsunami hazards. We generate a total of 6,300 stochastic tsunami source models from six magnitude scenarios between M 7.75 and M 9.0 and obtain time-dependent PTHA results for seven different periods $(1,5,10,20,30,50$ and 450 years). We further compare the time-dependent PTHA results with a time-independent PTHA approach to investigate the influence of the spatiotemporal earthquake rupture model. The spacetime interaction model successfully generates annual seismic moment rates consistent with the observations. Moreover, the model can capture the uncertainty of future time-dependent tsunami hazards. On the other hand, the time-independent approach produces slightly higher hazard estimates than the time-dependent model for long-term hazard assessments (> 450 years).

\section{Introduction}

25 Massive tsunamigenic earthquakes have occurred in recent years and caused devastating effects in tsunami-prone areas. Globally, in the last 50 years, seventeen significant tsunami earthquakes occurred, claiming a total economic loss exceeding $\$ 14$ trillion and almost 290,000 deaths (USGS, 2020). Two notable tsunamigenic events contributing to these significant economic losses and fatalities were the 2004 Aceh-Andaman tsunami in Indonesia (Rossetto et al., 2007) and the 2011 Tohoku-Japan tsunami (Raby et al., 2015). Over the next decades, major tsunamigenic events are anticipated in several 
30 subduction zones. These include the Mexican subduction zone (Mori et al., 2017), the Nankai-Tonankai Trough (Goda et al., 2020), the Makran subduction zone (Momeni et al., 2020), the Hikurangi subduction zone (Wallace et al., 2016), the Philippines subduction zone (Løvholt et al., 2012), the Cascadia subduction zone (Park et al., 2017), and the Mentawai region of the Sunda subduction zone (Muhammad et al., 2017). Therefore, comprehensive tsunami risk mitigation in these tsunami-prone areas is essential.

A fundamental requirement to assess tsunami risk and determine effective tsunami risk mitigation strategies is Probabilistic Tsunami Hazard Analysis (PTHA). In general, PTHA can be carried out in four stages: (1) earthquake occurrence modelling and rupture area characterization, (2) tsunami source generation, (3) tsunami propagation and inundation, and (4) tsunami hazard estimation. Regarding earthquake occurrence modelling, the current state-of-the-art approach employs a memory-less Poisson process for long-term hazard assessment and is commonly adopted in previous

40 PTHA studies (Burroughs and Tebbens, 2005; Tinti et al., 2005; Orfanogiannaki and Papadopoulos, 2007). However, assuming a lack of memory between major earthquake occurrences is often viewed as a first approximation, inconsistent with the physics of elastic rebound (Reid, 1911; Anagnos and Kiremidjian, 1984; Berryman et al., 2012). As a result, many have adopted a renewal model of earthquake occurrence (Matthews et al., 2002; Zhuang et al., 2012; Field et al., 2014) to carry out a time-dependent analysis, specifically for probabilistic seismic hazard analysis (PSHA; Akinci et al., 2005; Field et al., 2014). Recently, Goda (2019) and Fukutani et al. (2021) applied this approach to PTHA. In addition, Ceferino et al. (2020) developed a new space-time earthquake occurrence model by characterizing spatiotemporal interactions of major tsunamigenic events as a correlated, multivariate Bernoulli process of neighboring segments each obeying marginal Brownian passage-time (BPT) recurrence distributions. Their model includes spatial correlations between ruptures and yet guarantees prescribed marginal distributions on each segment via copulas.

Furthermore, recent tsunami hazard assessments have progressed significantly in earthquake source modelling. For instance, stochastic earthquake source modelling considering the uncertainty and dependency of earthquake source parameters has been adopted to estimate the tsunami hazard in tsunami-prone regions (e.g. Mori et al., 2017; Park et al., 2017; Momeni et al., 2020). Recent work has also used high-resolution spatial grids to simulate tsunamis to produce more accurate tsunami hazard results (e.g. <90 m; Griffin et al., 2016; Goda et al., 2020). These recent advances in stochastic source modelling should be integrated into PTHA.

In this study, we develop a novel time-dependent PTHA framework that combines a space-time earthquake interaction model with stochastic source modelling and high-resolution tsunami simulations for the Mentawai region of the Sunda subduction zone in Indonesia. We implement the space-time earthquake occurrence model developed by Ceferino et al. (2020) to characterize the occurrence of future earthquake ruptures. This approach models ruptures on individual

60 segments with temporal renewal processes and prescribes spatial correlation between ruptures in neighboring segments to enable multi-segment ruptures. To characterize realistic earthquake rupture patterns for assessing tsunami hazard, we incorporate stochastic earthquake source scenarios, including uncertainties in the size of the rupture plane and spatial heterogeneity of earthquake slip (Muhammad et al., 2016). In other words, the proposed time-dependent earthquake rupture 
modelling method combines the spatiotemporal interaction earthquake occurrence model by Ceferino et al. (2020) and the stochastic-source PTHA method by Muhammad et al. (2016) to enable time-dependent PTHA based on segmented earthquake rupture sources. The proposed framework is then implemented to carry out PTHA due to future tsunamigenic events generated in the Mentawai region. Since the time-dependent hazard estimation leads to more realistic short-term results (e.g. $<50$ years) compared to long-term assessments with a Poisson process, adopting the new time-dependent PTHA approach is more appropriate for the Mentawai-Sunda zone, where major tsunamigenic events are impending over the next few decades based on paleogeodetic and paleotsunami studies (Philibosian et al., 2014, 2017).

In a national context, PTHA for Indonesia was developed by Horspool et al. (2014). However, limitations of the current tsunami hazard assessment in Indonesia include: (1) a time-independent Poisson process of earthquake occurrence was adopted, which is inconsistent with time-dependent hazard estimation over a short period, (2) a uniform slip of earthquake rupture was used, which could underestimate tsunami hazard (e.g. Muhammad et al., 2018), and (3) coarse grids, i.e. $\sim 1,800 \mathrm{~m}$ in the coastal region and $\sim 5,400 \mathrm{~m}$ in deep ocean areas (below 1,000 $\mathrm{m}$ ), were implemented for tsunami simulation, without performing detailed run-up simulations. By adopting a finer tsunami simulation grid $(50 \mathrm{~m})$ together with more realistic heterogeneous earthquake slip models, we improve the prior work by Horspool et al. (2014) by accounting for the variability and uncertainty of the earthquake source models as well as the time-dependent earthquake occurrence.

To carry out the analysis, we first collect supercyclic earthquake data since the $16^{\text {th }}$ century (a 450 -year period) in the Mentawai region from paleogeodetic measurements (Natawidjaja et al., 2006; Sieh et al., 2008; Philibosian et al., 2014, 2017). The past fault rupture areas can be used to construct the potential fault rupture areas of the earthquake occurrence model. The term supercyclic refers to a long-term cluster of differently sized megathrust earthquakes leading to the final complete failure across multiple segments of a subduction zone (Herrendörfer et al., 2015). Second, based on the fault rupture areas and occurrence times of the past earthquakes, we build a space-time interaction model of the large earthquake ruptures (Ceferino et al., 2020). Third, the defined fault rupture area is further divided into several segments representing six magnitude ranges, namely $\mathrm{M} 7.75,8.0,8.25,8.5,8.75$, and 9.0, which we use to define the rupture areas for the stochastic earthquake source generation (Muhammad et al., 2016). Fourth, we simulate stochastic tsunamis with a fine grid of $50 \mathrm{~m}$ by solving nonlinear shallow-water wave equations (Goto et al., 1997). We target the coastal areas of three key cities, namely

90 Pariaman, Padang, and Painan. Fifth, we model earthquake rupture with the space-time interaction approach over seven periods, namely $1,5,10,20,30,50$ and 450 years. In this study, we mostly focus on the short period ( $<50$ years), whereas the 450 years is considered as a representation of a longer period and corresponds to the period of the past earthquake data used in the study area (i.e. from 1597 to 2010). Finally, we derive site-specific tsunami hazard curves and tsunami hazard maps (i.e. maximum tsunami wave heights).

The paper is organized as follows. Section 2 presents the new methodology for time-dependent PTHA, including the time-independent and time-dependent models (section 2.1), earthquake rupture modelling with space-time interaction (section 2.2), and the stochastic earthquake source generation and tsunami simulation (section 2.3). Section 3 presents results 
and discussion of the Bayesian parameter estimation of the occurrence model (section 3.1), earthquake rupture modelling (section 3.2), and time-dependent PTHA (section 3.3). This section also compares the hazard curves and maps of the timedependent PTHA with the time-independent approach.

\section{Methodology}

\subsection{PTHA framework}

\subsubsection{Time-independent formulation}

Time-independent PTHA assumes that tsunamigenic earthquake occurrence follows a Poisson process. The probability of observing the occurrence of a maximum tsunami height $H$ equal to or greater than a specific value $h$ in $t$ years and at a specific location is:

$P(H \geq h \mid t)=1-\exp [-\lambda(H \geq h) \cdot t]$

where $\lambda(H \geq h)$ is the mean annual rate of $H \geq h$. The term tsunami height used in this paper is the height of water flow above the mean sea level. Moreover, the tsunami depth refers to the height of water flow above ground level. Subtracting the ground elevation from the tsunami wave height at the place of interest yields the depth.

The mean annual rate $\lambda(H \geq h)$ can be expressed as a filtered Poisson process (Parsons and Geist, 2009):

$\lambda(H \geq h)=\sum_{i=1}^{N_{\text {sources }}} \lambda_{i}\left(M \geq M_{\min }\right) \cdot \int P_{i}(H \geq h \mid \theta) \cdot S(\theta \mid M) \cdot f_{i}(M) \cdot d M$

where $N_{\text {sources }}$ is the number of tsunami sources and $\lambda_{i}\left(M \geq M_{\min }\right)$ is the mean annual rate of earthquakes larger than $M_{\min }$ of the $i$ th source. The term $P_{i}(H \geq h \mid \theta)$ represents the probability of a specific hazard measure $H$ exceeding a pre-defined

115 value $h$ at a location for given tsunami source parameters $(\theta) . f_{i}(M)$ is the magnitude-frequency distribution characterizing the $i$ th source, whilst $S(\theta \mid M)$ is the distribution of the uncertain source parameters conditioned on the earthquake magnitude. The frequency-magnitude distribution can be defined by a truncated Gutenberg-Richter (GR) relationship:

$F(M)=\frac{1-10^{-b \cdot\left(M-M_{\min }\right)}}{1-10^{-b \cdot\left(M_{\max }-M_{\min }\right)}}, \quad M_{\min } \leq M \leq M_{\max }$

where the $b$ value in Equation (3) is estimated from the seismicity data of the Advanced National Seismic System (ANSS) catalog (https://earthquake.usgs.gov/data/comcat/; see Figure 1A). Figure 1B shows the $b$ value estimated from seismicity data between 1970 and 2015 in the Mentawai region of the Sunda subduction zone using the maximum likelihood estimation method (Aki, 1965).

To apply stochastic earthquake sources to PTHA, De Risi and Goda (2017) approximated the continuous $f(M)$ with a discrete magnitude function $P\left(M_{j}\right)(j=1, \ldots, n)$ of $n$ bins with bin width $\Delta M$ (Figure 1D). The discrete probability can be calculated from

$P\left(M_{i}\right)=F\left(M_{i}+0.5 \cdot \Delta M\right)-F\left(M_{i}-0.5 \cdot \Delta M\right)$.

Hence, we can replace Equation (2) integral with a summation over discrete magnitude bins. Moreover, the mean annual rate $\lambda_{i}\left(M \geq M_{\min }\right)$ of seismic events greater than $M_{\min }$ can be calculated from the fitted GR curve shown in Figure 1C. In this 
study, we consider an $M_{\min }$ of 7.625 and a $\Delta M$ of 0.25 with six central magnitude values are M 7.75, M 8.0, M 8.25, M 8.5, M 8.75, and M 9.0. This minimum value is suitable for PTHA because the tsunami hazards from earthquakes smaller than M 7.625 is rarely significant (Muhammad et al., 2016).

\subsubsection{Time-dependent algorithm}

The PTHA framework can be modified to include a renewal occurrence model for time-dependent PTHA. The recurrence of tsunamigenic events is assumed to be quasi-periodic and depends on the time since the last earthquake. The lognormal and the BPT distribution have been widely used to describe seismic recurrences for PSHA (Convertito et al., 2012; Field et al., 2014; Ceferino et al., 2020). We thus adopt the BPT distribution (Matthews et al., 2002) to estimate the (marginal) probability of tsunamigenic inter-arrival times. Moreover, we include space-time interaction in the time-dependent PTHA via a spatially correlated rupture model.

Figure 2 shows our approach to conduct time-dependent PTHA. This section presents a brief overview, while subsequent sections describe individual phases in detail. First, the earthquake source zone is defined and discretized into segments, each representing the minimum possible ruptured area corresponding to an M7.625 event (see red line arrows in Figure 2A). The source zone and segments are developed from historical and instrumental data of large earthquakes in the Mentawai-Sunda zone in the last 450 years (see Figure 2A). Second, using this source geometry model, we generate earthquake ruptures (see Figure 2B) and stochastic source scenarios (see Figure 2C), considering the uncertainty and dependency of earthquake source parameters. Crucially, ruptures are time-dependent and spatially correlated. Third, we simulate tsunami propagation and inundation based on the stochastic earthquake source models to obtain the tsunami hazard level in the target region (see Figure 2C). Fourth, we determine the probability $P(H \geq h \mid t)$ of a hazard metric $H$ (i.e. tsunami height) exceeding a specific $h$ value at a given location over a given period $t$ (see Figure 2D).

The hazard curves $P(H \geq h \mid t)$ are calculated by combining the rupture modelling and the tsunami simulation results. As described in more detail below (see section 2.2.1), the occurrence model produces earthquake catalogs with 21 distinct geometrical rupture scenarios spanning six discrete magnitude levels, namely M 7.75, M 8.0, M 8.25, M 8.5, M 8.75, and M 9.0. Each event may rupture one or multiple segments depending on the magnitude. For example, M 7.75 and M 9.0 events rupture one and five segments, respectively. Furthermore, for each of those 21 rupture scenarios, we generate 300 stochastic source models, which set initial conditions for the corresponding tsunami inundation simulations (see section 2.2.1 and section 2.3) to obtain a total of 6,300 tsunami simulations at $50 \mathrm{~m}$ grid resolution in coastal areas.

Figure 3 shows the procedure to develop the final hazard curve for the time-dependent model. First, we select a total number of simulated earthquake catalogs $N_{\text {sim }}$. Second, three results from each earthquake rupture catalog and from the stochastic tsunami simulations are obtained, namely (1) the simulated earthquake catalogs, (2) the number of occurred scenarios $\left(N_{s c e}\right)$, and (3) the stochastic simulated heights corresponding to the occurred scenarios. Note that $N_{s c e}$ counts the number of events (i.e. if the same scenario occurs twice in a $t$-year catalog, then they are counted as two events). Based on 
the occurred scenarios, the stochastically simulated heights are obtained for each occurred scenario, randomly chosen from a total of 300 simulated heights (i.e. the number of stochastic simulations for each scenario is 300). This height is then stored for each occurred scenario. Those stored heights are further used to define the maximum height for each catalog (i.e. one height for one simulation catalog). The above procedure is then repeated for all rupture catalogs and hence, a total of $N_{\text {sim }}$ maximum heights are stored in each $t$-year simulation. These height data are finally used to generate the mean hazard curve using the Complementary Cumulative Distribution Function (CCDF). Thus, only one final hazard curve for each $t$ period is generated.

To determine a suitable value of $N_{\text {sim }}$, we first examine the stability of the simulated catalogs by calculating the relative frequency of each scenario as a function of increasing $N_{\text {sim }}$. The relative frequency is the ratio of the occurrences of

170 a scenario to the total number of occurred events in a target period of simulation (e.g. 1 year). A total of 100,000 earthquake rupture simulations are carried out for all seven periods i.e. 1, 5, 10, 20,30, 50, and 450 years, with a starting simulation time of 2021 (i.e. year $0=2021$ ). The results confirm that $N_{\text {sim }}=100,000$ catalogs are sufficient to produce a stable result and hence, we use $N_{\text {sim }} \geq 100,000$, varied for different periods. From an earthquake-tsunami mitigation perspective, the return period of several thousand (e.g. 2,500 years) is generally relevant for tsunami hazard mapping purposes. Moreover, the tsunami hazard at a lower probability level, i.e. $4 \times 10^{-4}$ and $2 \times 10^{-3}$, may be used to evaluate the tsunami hazard for 1 year and 5 years, respectively (i.e. the return period at these two lower probability levels is 2,500 years). Therefore, we adopt $10,000,000$ catalogs for 1-year earthquake rupture simulations to obtain sufficient results at the probability level of $10^{-4}$. On the other hand, the number of simulations is reduced by a factor of 10 at longer durations, i.e. a total of 1,000,000 and 100,000 simulation numbers are used for 5 to 50 years and 450 years, respectively.

\subsection{Earthquake rupture modelling with space-time interaction}

Ceferino et al. (2020) developed a space-time-dependent earthquake occurrence model, combining elements of elastic rebound theory with spatial rupture clustering at segment level in a relatively compact statistical formulation. In this model, the time between failure states (inter-arrival time) follows the BPT distribution, which arises from a Brownian Relaxation Oscillator (BRO) to represent the stress accumulation on faults (Matthews et al., 2002). The BRO resets the stress when it reaches the failure threshold and thus reflects elastic rebound. Moreover, spatial stress interaction among neighbouring fault segments is modeled with a spatial correlation function represented by a spherical variogram model (Ceferino et al., 2020). Parameters are the mean $(\mu)$ and coefficient of variation $(\alpha)$ for each segment of the BPT distribution and the spatial decay rate $(\gamma)$ for the spatial correlation of the segment ruptures (see section 2.2.2). Typically, the maximum likelihood estimation (MLE) is used to estimate rupture model parameters (Ogata, 1999; Zhuang et al., 2012), but the MLE is not robust when data

190 are scarce, as is the case in the Mentawai-Sunda zone. For instance, there were only two ruptures over 450 years in one particular segment (i.e. segment 6): the 1658 and 1797 events (see Figure 6A). We, therefore, use a Bayesian method 
(Gelman et al., 2013; Ceferino et al., 2020) to estimate the model parameters. The following sections contain detailed descriptions of the procedures to model the earthquake rupture occurrence process.

\subsubsection{Determination and segmentation of fault areas}

195 We first define the source areas of the fault (see Figure 2A), focusing on the Mentawai region of the Sunda subduction zone. We collect supercyclic earthquake data of the Mentawai-Sunda subduction zone from the literature to define the tsunamigenic source geometry. Over the last 450 years, a total of 10 significant tsunamigenic events (> M 7.625) contributed to regional tsunami hazards (see Table 1). This number is consistent with the G-R model with at least one event (>M 7.625) every $\sim 50$ years (see Figure 1). The dates and spatial extents of the ruptures before the $19^{\text {th }}$ century were inferred by Philibosian et al. (2017) from paleogeodetic measurements in the Mentawai areas (see Figure 4). Specifically, coral microatoll samples from 21 sites along $600 \mathrm{~km}$ of the Mentawai region were used to constrain the dates, spatial extents and approximate earthquake source models (Natawidjaja et al., 2006; Shieh et al., 2008; Philibosian et al., 2014, 2017). Earthquake source models of recent tsunamigenic earthquakes (after 2000) were estimated from geodetic, seismic, and field measurements (Konca et al., 2008; Yue et al., 2014; see Figure 5). These finite-fault models contain areas of insignificant slip along the edges (see Figure and Figure 5). Including these results in overestimated rupture areas (Mai and Beroza, 2002) and produces incorrect rupture lengths for the scenarios. We, therefore, exclude areas of insignificant slip by an effective dimension analysis. Further details about this analysis can be found in Mai and Beroza (2002) and Muhammad et al. (2016).

Using the above earthquake source models, we then define a one-dimensional (1D) representation of the fault from the effective along-strike lengths of the finite-fault models (see dark green color in Figure 6A). This 1D fault is then discretized into six segments with a length of $100 \mathrm{~km}$ that corresponds to a minimum magnitude (M 7.75) of a significant tsunami-earthquake (see Figure 6B) and is consistent with the scaling relationship by Goda et al. (2016). This segmentation is an essential component of the space-time rupture model (see section 2.2.2). This minimum magnitude (i.e. M7.75) is the same as the central of the minimum magnitude for the PTHA of the time-independent model (i.e. see section 2.1.1).

To integrate the space-time rupture model and the stochastic source scenarios, we map simulated ruptures (Figure 6A and right panel of Figure 6B) onto discrete scenarios (left panel of Figure 6B) representing tsunami sources. Moreover, this setup is essential, allowing a good balance between the number of simulations and the spatial discretization of the fault area. A total of 21 source scenarios are developed to represent six magnitude levels (M 7.75, M 8.0, M 8.25, M 8.5, M 8.75, and $M$ 9.0). The first six scenarios represent the minimum magnitude scenario (M 7.75). Moreover, the $7^{\text {th }}$ to the $11^{\text {th }}$ scenarios, the $12^{\text {th }}$ to the $15^{\text {th }}$ scenarios, the $16^{\text {th }}$ to the $18^{\text {th }}$, and the $19^{\text {th }}$ scenario are for the M 8.0, M 8.25, M 8.5, M 8.75, and M 9.0 events, respectively (Figure 6B).

Each magnitude scenario is set up to a fixed length interval following the rupture length of the segment in the earthquake rupture modelling (see the length of each segment in Figure 6B). The maximum length of each magnitude is based on the total number of ruptured segments for each scenario. For example, the maximum length for the M 8.0 case is $200 \mathrm{~km}$ because two segments rupture in this scenario. When the ruptured length is more than half of the segment length 
(e.g. $>160 \mathrm{~km}$ for the M 8.0 case), the entire segment is involved in rupture simulations. The maximum and minimum lengths of each magnitude scenario are listed in Table 2.

\subsubsection{Space and time interaction approach}

We adopt the space-time interaction approach by Ceferino et al. (2020) to model earthquake ruptures (Figure 7A). First, the 1D along-strike distance is discretized into 6 segments to represent the smallest areas that may rupture in tsunamigenic earthquakes (see Figure 7A and section 2.2.1). Second, we set the rupture state of each segment $k$ at time $t, \boldsymbol{X}_{\boldsymbol{t}}(k)$, equal to 1 when a rupture occurs, and 0 otherwise. The rupture vector $\boldsymbol{X}_{\boldsymbol{t}}(k)$ depends on the rupture probability of each segment in year $t$ conditioned on the time elapsed since the last earthquake, $\boldsymbol{X}_{\boldsymbol{t}} \mid \boldsymbol{T}_{\boldsymbol{t}}$, and is calculated according to a multivariate Bernoulli distribution (Figure 7C):

$\boldsymbol{X}_{\boldsymbol{t}} \mid \boldsymbol{T}_{\boldsymbol{t}} \sim$ Multivariate Bernoulli $\left(p_{t}, \Sigma\right)$

where $\boldsymbol{T}_{\boldsymbol{t}}$ is the vector of elapsed time since the last rupture on each segment, $\boldsymbol{T}_{\boldsymbol{t}}=\left\{T_{t}(1), \ldots, T_{t}(6)\right\}$ and is updated based on the rupture occurrence $\left(\boldsymbol{X}_{\boldsymbol{t}}\right)$. The relationship between $\boldsymbol{T}_{\boldsymbol{t}}$ and $\boldsymbol{X}_{\boldsymbol{t}}$ can be written as:

$T_{t+1}=T_{t}(k)\left\{1-X_{t}(k)\right\}+1$

The two parameters $\boldsymbol{p}_{\boldsymbol{t}}$ and $\Sigma$ in Equation (5) describe the temporal and spatial interaction, respectively. $\boldsymbol{p}_{\boldsymbol{t}}$ is a vector of the marginal probability of rupture on the $k$-th segment in year $t$ given the time since the last rupture $\left(T_{t}\right) . \Sigma$ is a 6by-6 covariance matrix describing the spatial correlation of ruptures on the segments (see Figure 7C)

$\boldsymbol{p}_{\boldsymbol{t}}$ is calculated using the BPT cumulative distribution function and represents the rupture probability during a given year conditional on no rupture since $T_{t}$ (Matthews et al., 2002; Zhuang et al., 2012; see left panel of Figure 7C):

$p_{t(k)}=\frac{F\left(T_{t}(k)+1\right)-F\left(T_{t}(k)\right)}{1-F\left(T_{t}(k)\right)}$

where $F(t)$ is the BPT cumulative distribution function of inter-event waiting times defined by (Matthews et al., 2002):

$F_{k}(t)=\Phi\left[\alpha_{k}^{-1}\left[t^{\frac{1}{2}} \mu_{k}^{-\frac{1}{2}}-t^{-\frac{1}{2}} \mu_{k}^{\frac{1}{2}}\right]\right]+e^{2 / \alpha_{k}^{2}} \Phi\left[-\left(\alpha_{k}^{-1}\left[t^{\frac{1}{2}} \mu_{k}^{-\frac{1}{2}}+t^{-\frac{1}{2}} \mu_{k}^{\frac{1}{2}}\right]\right)\right]$

We use a Bayesian approach to estimate the BPT parameters, i.e. mean $(\mu)$, coefficient of variation $(\alpha)$ and decay rate $(\gamma)$ (see Figure 7B). The Bayesian approach (Gelman et al., 2013) applied to a 450-year catalog produces the posterior distribution of those parameters. A lognormal prior is adopted to carry out Bayesian simulation with the following parameters:

1. The prior median of $\mu$ for each segment is different, namely $174,50,40,45,134$, and 100 years for the segments 1 to 6 , respectively. These values represent the median interarrival time of earthquake rupture on each segment over the last 450 years. We set the prior logarithmic standard deviation of $\mu$ to 0.3 as it represents the deviation of the interarrival time data.

2. We set the prior median of $\alpha$ to 0.7 in common with other time-dependent hazard assessments (Field et al., 2014; Ceferino et al., 2020). We adopt a prior logarithmic standard deviation of 0.3 . 
On the other hand, the spatial correlation $(\rho)$ among segments is represented by a spherical correlogram model (Ceferino et al., 2020). It defines the correlation of ruptures between segments $k$ and $l$ of the fault as a function of distance $D$ with a decay rate $\gamma$ (see right side of Figure 7C):

$\rho_{k, l}=\exp \left(-\left(\frac{D_{k, l}}{\gamma}\right)^{2}\right)$

We estimate the decay rate $\gamma$ with the Bayesian approach along with the BPT parameters. We fix the prior median and logarithmic standard deviation of $\gamma$ to $400 \mathrm{~km}$ and 0.3 , respectively, because the mean historical rupture length is about this size. The following equations (Equation (10)) show the formulae to estimate the posterior probability of the three parameters:

$P\left(\mu_{k}, \alpha_{k}, \gamma \mid X\right)=\frac{P\left(X \mid \mu_{k}, \alpha_{k}, \gamma\right) P\left(\mu_{k}, \alpha_{k}, \gamma\right)}{\iiint P\left(X \mid \mu_{k}, \alpha_{k}, \gamma\right) P\left(\mu_{k}, \alpha_{k}, \gamma\right) d \mu_{k} d \alpha_{k} d \gamma}$

$P\left(\mu_{k}, \alpha_{k}, \gamma\right)=P(\gamma) \prod_{k=1}^{N} P\left(\mu_{k}\right) P\left(\alpha_{k}\right)$

$P\left(X_{t} \mid \mu_{k}, \alpha_{k}, \gamma\right)=\prod_{t=1}^{n_{\text {years }}} P\left(X_{t} \mid T_{t}\right)$

$P\left(X_{t} \mid T_{t}\right)=P\left(\cap_{k=1}^{N} A_{k}\right)$, where $\left\{\begin{array}{l}A_{k}=\left\{Z_{t}(k)>\Phi^{-1}\left[p_{t}\right]\right\} \text { if } X_{t}=0, \\ A_{k}=\left\{Z_{t}(k) \leq \Phi^{-1}\left[p_{t}\right]\right\} \text { if } X_{t}=1\end{array}\right.$

To estimate the posterior, we first model the prior distribution using a multivariate lognormal distribution as presented in Equation (11) in each segment (i.e. $N=6$ ). Second, we calculate the likelihood, $P\left(X_{t} \mid \mu_{k}, \alpha_{k}, \gamma\right)$, based on the available rupture data (Equation (12)). It can be estimated as the product of the annual rupture occurrence probability distributions, $P\left(X_{t} \mid T_{t}\right)$, representing the probability of being in the intersection volume $A_{k}$, where $A_{k}$ is equal to either $Z_{t}(k)>\Phi^{-1}\left[p_{t}\right]$ when there is no rupture in year $t$ in the $i$ th segment, and $Z_{t}(k) \leq \Phi^{-1}\left[p_{t}\right]$ otherwise (Equation (13)). Finally, we compute the denominator of the posterior with a Markov Chain Monte Carlo (MCMC) approach using the Metropolis Hasting (MH) algorithm (Chib and Greenberg, 1995).

\subsubsection{Earthquake rupture simulation}

We use the estimated parameters to simulate earthquake ruptures using Equation (5). To obtain samples from the correlated multivariate Bernoulli distribution (Equation (5)), which cannot be written in a closed form, Ceferino et al. (2020) adopted a copula method (Jin et al., 2015) to obtain approximate samples (Equation (14)). Figure 7D illustrates the procedure to sample rupture occurrence of each segment with the Gaussian copula. First, we generate correlated normally distributed random variables $\left(\boldsymbol{Z}_{\boldsymbol{t}}\right)$ with zero mean and a covariance matrix $\Sigma$ defined by the correlogram model (Equation (9)) using 
Equation (14). The matrix size of the correlogram model is based on the total number of segments, i.e. the size of the matrix is $N \times N$ where $N=6$ (i.e. a total number of segments):

$\boldsymbol{Z}_{\boldsymbol{t}} \sim \mathcal{N}\left(0, \Sigma_{k, l}\right)$, where $\Sigma_{k, l}=\rho_{k, l}$.

We then transform $Z_{t}$ using the standard normal cumulative distribution function $\Phi\left(Z_{t}\right)$ to obtain correlated, uniformly distributed random variables in $[0,1] . X_{t}$ is set to 1 (rupture has occurred) when $Z_{t}$ is smaller than $p_{t}$ from Equation (7) and set to 0 otherwise:

$X_{t(k)}=\mathbb{1}\left\{\Phi\left(Z_{t}(k)\right)<p_{t}(k)\right\}$.

The bottom panel of Figure 7D illustrates a synthetic rupture catalog simulated with the copula approach by sampling the correlated multivariate Bernoulli distribution. The profile of ruptures at the 20th year of simulation (highlighted by the red line in Figure 7D shows that segments 4, 5, and 6 have ruptured because their $\Phi\left(Z_{t}\right)$ values are both less than $p_{t}$, whereas other segments do not rupture.

Finally, we carry out Monte Carlo earthquake rupture simulations. First, the number of t-years earthquake catalogs is set to $N_{\text {sim }} \geq 100,000$ (see section 2.1.2). Second, using the spatial correlation among the segments $\left(\rho_{k, l}\right)$ (Equation (9)) and the initial elapsed time since the last past earthquake $\left(T_{t}\right)$, we simulate correlated rupture probabilities in one-year increments with the copula method. We then determine rupture occurrences in year $t\left(\boldsymbol{X}_{\boldsymbol{t}}\right)$ using (Equation (15)) in each segment. We finally repeat the procedure to obtain $\geq 100,000$ catalogs over the periods of interest.

\subsection{Stochastic earthquake source generation and tsunami simulation}

We estimate tsunami hazard in the region of interest via a Monte Carlo tsunami simulation (see Figure 2C) by generating stochastic earthquake source models. To generate source models, we first sample earthquake source parameters, including rupture width $(W)$, mean slip $\left(D_{\mathrm{a}}\right)$, maximum slip $\left(D_{\mathrm{m}}\right)$, Box-Cox parameter $(\lambda)$, correlation length along strike direction $\left(A_{\mathrm{x}}\right)$, correlation length along dip direction $\left(A_{\mathrm{z}}\right)$, and Hurst number $(H)$. We use the empirical scaling relationships for global subduction earthquakes derived by Goda et al. (2016) because they are consistent with the source parameters of the past tsunamigenic events in the Sunda subduction zone (Muhammad et al., 2016).

Among these source parameters, the rupture length $(L)$ is pre-defined at the beginning of the simulation to integrate the tsunami hazard assessment and the earthquake rupture modelling. The length is calculated based on the magnitude and fault segmentation (see section 2.2.1). Therefore, given a pre-defined fault length, we randomly draw the other source parameters from the source scaling relationships. To ensure the consistency of the generated source parameters using the scaling relationships, we require that the simulated seismic moment $\left(\mathrm{M}_{\mathrm{o}}=\mu W L D_{a}\right.$, where $\mu$ is the rock rigidity) is within a tolerance of plus/minus 0.1 magnitude units of the target moment of a magnitude scenario. We assume a rigidity of $40 \mathrm{GPa}$, which is typical for the Sunda subduction zone (Natawidjaja et al., 2006; Kongko et al., 2011). As a result, we produce 
simulated values of $\mathrm{W}$ and Da iteratively until the seismic moment condition is met (i.e. $L$ has been pre-defined at the beginning of the simulation).

We next develop stochastic source models. We first generate a random field using the Fourier integral method (Mai and Beroza, 2002) based on the simulated spatial slip distribution parameters. We use a Box-Cox transformation to obtain slip distributions with realistic positive skewness. We adjust the transformed slip distribution to achieve the target mean slip, $D_{\mathrm{a}}$, and avoid very large slip values exceeding the maximum target slip, $D_{\mathrm{m}}$. Muhammad et al. $(2016,2017)$ provide further details about this method. Based on a stability test of the tsunami simulations, 300 stochastic models are sufficient to simulate stable and consistent tsunami heights and depths (De Risi and Goda, 2017). We generate 300 source models for each scenario for a total of 6,300 stochastic source slip models.

Given the source models, we simulate tsunamis to estimate the tsunami hazard along the western coast of Sumatra, which requires a digital elevation model (DEM) and bathymetry data. Bathymetry data are taken from the GEBCO2014 dataset (http://www.gebco.net/data_and_products/gridded_bathymetry_data/), $\quad$ whilst $\quad$ SRTM1 (https://lta.cr.usgs.gov/SRTM1Arc) is used for the DEM data (see Figure 8A). For areas around the target zone of Pariaman, Padang, and Painan, we adopt local DEM (DEM5) and Bathymetry (Bathy5) within a nested grid system of four resolution levels. Therefore, the tsunami simulation grid for Sumatra are 1,350 m (red box in Figure 8B), $450 \mathrm{~m}$ (green box in Figure 8B), $150 \mathrm{~m}$ (magenta box in Figure 8B), and $50 \mathrm{~m}$ (blue box in Figure 8B). The 1,350 m region encompasses all of Western Sumatra.

Once stochastic source models are generated, and the DEM/bathymetry data are constructed, we calculate the initial water surface elevation using formulae by Okada (1985) and Tanioka and Satake (1996) that consider the deformation due to both vertical and horizontal displacements of the seafloor. Tsunami waves are then propagated by solving the nonlinear shallow water equation with runup (Goto et al., 1997). The effects of surface roughness on tsunami flows are modelled with Manning's bottom friction formula with a uniform roughness coefficient of $0.025 \mathrm{~m}^{-1 / 3} \mathrm{~s}$ for the ocean and $0.06 \mathrm{~m}^{-1 / 3} \mathrm{~s}$ for land (Griffin et al., 2016). The fault rupture is supposed to happen instantly, whilst the tsunami simulation runs for 2 hours with a time step of 0.5 seconds to meet the Courant-Friedrichs-Lewys requirement for bathymetry and elevation data for the

335 Mentawai region (Selvan and Kankara, 2016; Akoh et al., 2017). The above simulation procedure is run iteratively through a Monte Carlo simulation for all stochastic source models. Subsequently, tsunami simulation results at locations of interest are evaluated. Furthermore, the Monte Carlo tsunami simulation results can be used to assess the variability of tsunami simulation outcomes in terms of tsunami wave height at different locations (e.g. Pariaman, Padang, and Painan; see Figure 8C) and for developing probabilistic tsunami hazard assessments. 


\section{Results and Discussion}

\subsection{Bayesian Parameter Estimation}

Using the prior parameters (see section 2.2.2), the MCMC algorithm sampled 10,000 posterior models. The chain explores a 13-dimensional parameter space: six pairs of $\mu$ and $\alpha$, and one $\gamma$. The standard deviation of random walk steps for all $\mu$ and $\alpha$ and $\gamma$ are 12.5, 0.1 , and 25, respectively. These parameters produce an acceptance rate of $\sim 20 \%$, indicating good mixing (Chib and Greenberg, 1995; Sherlock and Roberts, 2009). We observe stable parameter estimates after a burn-in period of 500 steps.

Figure 9 illustrates the MCMC results with the priors and posteriors of $\mu, \alpha$, and $\gamma$ for all segments, whilst the final parameter estimates are taken from the maximum a posteriori (MAP; Table 3). The figure shows that, in general, the available earthquake data can effectively reduce the parametric uncertainty of the priors, in particular for the $\mu$ parameter in segments 2 to 4 . The median interarrival times of the central segments (i.e. segments 2 to 4 ) are about 40 years, while the interarrival times in the remaining segments are more than $50 \%$ greater. The uncertainties of the parameters for the interarrival times of segments 1,5, and 6 are large because few ruptures have occurred in those segments (see Figure 6). Moreover, the data dispersion of the central segments is greater than in others, resulting in a higher coefficient of variation. On the other hand, the estimated $\gamma$ is about $500 \mathrm{~km}$, indicating substantial spatial correlation of ruptures. In general, the estimated parameters reflect the interarrival times and variations of the earthquake data (see Table 1 and Figure 6).

\subsection{Earthquake rupture modelling}

We model earthquake ruptures with the Bayesian parameter estimates (see section 2.2). To simulate earthquake ruptures over the seven considered periods, i.e. 1, 5, 10, 20, 30, 50, and 450 years, we first generate ruptures for the longest period (450 years) by considering a total of 100,000 catalogs. We then simulate ruptures for the 50 years with a total of 1,000,000 catalogs and further construct the other period catalogs (i.e. 5, 10, 20, and 30) based on the 50-year simulations. Finally, the 1-year rupture simulation is performed with a total of 10,000,000 catalogs. To validate the rupture simulations, we further compare the average annual seismic moment release simulated over 450 years with the observed moment release. The seismic moment, $M_{0}$, is calculated for each segment according to (Hanks and Kanamori, 1979) in units of $10^{-7} \mathrm{Nm}$ :

$M=\frac{2}{3} \log \left(M_{0}\right)-10.7$.

365 The calculated seismic moments for both simulations and observations of each event are distributed uniformly over each ruptured segment. We then sum $M_{0}$ within each segment and divided by 450 years. Figure 10 compares the average annual moment release between the 450-year simulation and the observed historical data. The figure shows that the simulations are consistent with the data and hence, reasonably approximate rupture catalogs for the time-dependent PTHA.

We then present an example of one simulated catalog (number 152) for the next 5, 50, and 450 years in Figure 11.

370 The figure shows that for the short periods ( $\leq 50$ years), only a few earthquakes occur in the central segments 2 to 4 (Figure 
11A-B). The number of events increases significantly after 50 years (see Figure 11C). Moreover, to understand which scenarios are produced from the earthquake rupture simulation (see Figure 6B), Figure 12 provides a relative frequency of each scenario from the 100,000 catalogs of the seven periods, including 1, 5, 10, 20, 30, 50, and 450 years. In general, over the next 5 years, the chances of segments 1 to 4 and segments 2 to 4 rupturing simultaneously are relatively small. The relative frequency of scenario 16 (i.e. segments 1 to 4 ; see Figure 6B) is $0.0037 \%$, whereas the summed relative frequency of scenarios 12 (i.e. segments 1 to 3), 13 (i.e. segments 2 to 4), and 16 is about 19\%. Such a trend reflects the conditioning on past earthquake rupture history, i.e. in this context, segments 1 to 4 ruptured in 2007/2010, so the chances are small that another large one will happen here soon.

In general, the results (Figure 11C) show that segments 1, 5, and 6 have fewer ruptures due to greater recurrence intervals (i.e. $\sim 120$ years to $\sim 180$ years) than segments 2 , 3, and 4 with shorter interarrival times (i.e. $\sim 40$ years). Consequently, scenarios 8 and 13 occur the most, followed by scenario 9. To produce significant tsunamigenic events (>M 8.75), at least five segments need to rupture. Subsequently, the relative frequency of these significant magnitudes (>M 8.75) is small (below $\sim 5 \%$ for the period of over 10 years). In addition, the number of significant tsunamigenic earthquakes greater than M 8.25 increases with longer periods (i.e. 450 years). The simulations also suggest that the number of an M 9.0 event over the next 450 years is non-zero (see Figure 12O). Longer periods of simulation ( $\geq 50$ years) approach the magnitude distribution presumed by the time-independent PTHA method. However, it is noted that the distributions of the timeindependent and time-dependent models are not identical: the time-independent case is based on the G-R assumption, whilst the time-dependent approach includes the effects of fault rupture interaction.

\subsection{Time-dependent PTHA}

This section presents the main time-dependent PTHA results, using the results of the rupture modelling and the stochastic tsunami simulations (see section 2.1.2). We first illustrate the development of a tsunami hazard curve representing the timeindependent and the time-dependent exceedance probability of tsunami height. Second, we compare time-dependent and time-independent PTHA. Finally, we present and discuss the PTHA for the entire western coast of Sumatra.

\subsubsection{Development of the tsunami hazard curve}

395 We illustrate the hazard curve development (section 2.1) at a location in Pariaman City (P1 in Figure 8C). In the timeindependent PTHA, the simulated tsunami heights of each magnitude/source are used to construct the empirical CCDF. The conditional hazard curve for each magnitude is further calculated as the product of the CCDF, and the probabilities of each magnitude (i.e. the probabilities of M 7.75, M 8.0, M 8.25, M 8.5, M 8.75, and M 9.0 are 0.47, 0.26, 0.14, 0.076, 0.042, and 0.023 , respectively; see Figure 1D). Subsequently, the mean annual rate, $\lambda(H \geq h)$, is calculated as a sum of the conditional

400 hazard of each magnitude multiplied by the mean annual rate $\lambda(M \geq 7.625)$, which is equal to 0.034 . The mean annual rate is estimated from the instrumental catalog of the Mentawai-Sunda zone. The mean annual rate parameter is finally used to calculate the probability $P(H \geq h \mid t)$ of exceeding a specific $h$ for a given $t$ years. 
Figure 13 visualizes the development of hazard curves for Pariaman City at the depth of about $0 \mathrm{~m}$ (P1 in Figure 8C) using the time-independent PTHA. First, all simulated heights from the same magnitude are combined and the CCDFs of those six magnitudes are calculated (see Figure 13A). The conditioned hazard curve of each magnitude and the final unconditional hazard curve are further generated and presented in Figure 13B and Figure 13C, respectively. Adopting the annual hazard rate in Figure 13C, a hazard curve for a given time window (i.e. 1, 5, 10, 20, 30, 50 and 450 years), $P(H \geq h \mid t)$, is then calculated using Equation (1) as presented in Figure 13D.

Figure 14 displays the development of hazard curves for the time-dependent PTHA at a location in Pariaman City (P4 in Figure 8C) generated from one catalog of ruptures over 50 years (again, catalog 152). Figure 14B presents one synthetic 50-year rupture catalog in which three tsunamigenic scenarios occurred (the $4^{\text {th }}, 8^{\text {th }}$, and $15^{\text {th }}$ scenarios, Figure 14A). The heights from the stochastic tsunami simulation are further taken from the corresponding scenarios and are presented in Figure 14C. One height for each scenario is then randomly chosen from the 300 simulated heights of each occurred scenario. Those sampled heights are further used to define the maximum height for each catalog (i.e. one height for one simulation catalog). Such procedures are then repeated for each rupture catalogue to produe a total of $N_{\text {sim }}$ maximum heights in a specific $t$-year simulation ( $N_{\text {sim }}$ for the 50-year simulation is $1,000,000$ catalogs). Using these maximum heights, the final hazard curve is finally developed following the procedure in section 2.1.2 and is presented in Figure 14D.

\subsubsection{Comparison of time-dependent and time-independent PTHA}

We first illustrate the differences between the time-dependent and time-independent PTHA in terms of hazard curves at three cities along the western coast of Sumatra, including P4 in Pariaman, P12 in Padang, and P25 in Painan located at depths between 0.5 and $1.5 \mathrm{~m}$ (see Figure $8 \mathrm{C}$ ). We then construct tsunami hazard maps from the time-independent, and timedependent PTHA approaches for comparison. Figure 15 shows a comparison of tsunami hazard curves in terms of $P(H \geq$ $h \mid t$ ) based on the time-dependent and time-independent PTHA (see magenta line in Figure 15) for 1, 5, 10, 30, 50, and 450 years.

For the 1-year case, the time-dependent PTHA generally produced a higher hazard probability than the timeindependent PTHA model, specifically at the tsunami height of $\leq 5 \mathrm{~m}$. At the tsunami height of $2 \mathrm{~m}$, where it is relatively hard to evacuate (Pregnolato et al., 2017), the time-dependent model is about 20-25\% higher than the time-independent model. This is due to the frequent earthquake ruptures in the central segments (segments 2 to 4 ) found in 5\% of the 10,000,000 catalogs. Past ruptures in the central segments have observed recurrence intervals between 3 (i.e. occurred 430 between 2007 to 2010) and 20 years (i.e. occurred between 1597 to 1613). Hence, the ruptures in the 1-year simulation are located mainly in the central segments of the Mentawai-Sunda zone. This trend persists along the coast of western Sumatra (Figure 16). This figure presents the mean hazard curves at all points along the western coast of Sumatra located at a depth between 0.5 and $3 \mathrm{~m}$, from P1 to P33 (see Figure $8 \mathrm{C}$ ). The figure confirms that the time-dependent probability of a tsunami height below 4-5 $\mathrm{m}$ is, in general, higher than the time-independent model at all points. 
In addition, similar differences between the time-independent and the time-dependent models persist over shorter periods, specifically for $\leq 20$ years (see Figure 15A-L). In contrast, the time-dependent probabilities of heights above $5 \mathrm{~m}$ over short periods are smaller than the time-independent model because almost no M 9.0 events occur during these periods (see Figure 12A-L). Moreover, starting from the period of 30 years, the time-independent mean hazard probabilities are $\sim 10$ $30 \%$ greater than the time-dependent model, particularly at the tsunami level of $>5 \mathrm{~m}$ for 30 and 50 years, respectively (see Figure 15M-R). However, the differences decrease with a longer period.

Over the 450-year simulation, the time-dependent and time-independent models generate similar hazard probabilities, particularly for heights less than $5 \mathrm{~m}$. However, differences remain noticeable above $5 \mathrm{~m}$. The following reasons can explain the differences. The chances of M 8.75 and M 9.0 events producing significant tsunami heights (>3 m) in the time-dependent model are very slim. This is indicated by the small relative frequencies of only $3.2 \%$ and $0.61 \%$ for the

M 8.75 and M 9.0 events, respectively. In contrast, the time-independent model prescribes a probability of $4.2 \%$ and $2.3 \%$ for the M 8.75 and M 9.0 events and hence, these two events may contribute more to the higher hazard probability values than in the time-dependent model. The small chance of having the M 9.0 events for the time-dependent model is also because the segments from the maximum past tsunamigenic events (i.e. the M 8.81797 and the M 8.91833 events) ruptured only four segments (see Figure 2A). Therefore, adopting this past characterization leads to a small number of future events with a magnitude of above M 8.75.

Moreover, the difference in hazard curves over the long period is due to the different approaches in modelling the recurrence of the tsunamigenic event. The time-dependent model adopted the temporal renewal processes considering the time since the last earthquake. In contrast, the time since the last earthquake does not feature in the time-independent model. With a recurrence time of a significant tsunamigenic event (> M 8.75) of $\sim 250$ years (see Figure 2A), the failure state of the time-dependent rupture model is reset on average every 250 years and hence, even for a period longer than 450 years, the hazard probability of the time-independent model will still exceed the time-dependent model.

Regionally, our results show that Painan City experiences greater tsunami hazards than the other two cities. The tsunami heights at the coast of Painan City can be as much as $15 \mathrm{~m}$ compared to $\sim 10-12 \mathrm{~m}$ in Pariaman and Padang (see Figure 15). Segments 2 to 4 of the Mentawai region have a greater rupture probability and are located close to Painan City, hence driving the tsunami hazard level higher than in the other two cities. However, the tsunami hazard levels in Pariaman and Padang are still significant, as shown by high probabilities $(\sim 40 \%)$ of tsunami heights greater than $2 \mathrm{~m}$. The tsunami evacuation would face major difficulty at this 2-m level of tsunami height (Pregnolato et al., 2017), leading to a significant number of fatalities (> 300 people; Muhammad et al., 2021). Therefore, a well-prepared tsunami mitigation system is extremely important along the western coast of Sumatra.

Differences over shorter periods are further exhibited in 50-year tsunami hazard maps. In general, 50 years are used to represent the hazard maps at different probability levels for hazard assessment purposes (Akinci, 2009; De Risi and Goda, 2017). For the time-independent approach, maps for different probabilities in 50 years may represent various return periods, e.g. $10 \%$ and $2 \%$ in 50 years correspond to return periods of 475 years and 2475 years, respectively. Figure 17 shows the 
tsunami hazard maps in Padang City based on the time-dependent and time-independent methods for two different probabilities (10\% and 2\%) in 50 years. The maps are only developed for Padang City because a high-resolution $(\sim 5 \mathrm{~m})$ of DEM and bathymetry is used to construct the tsunami simulation dataset, producing a realistic inundation level over land. In Figure 17, depth indicates the hazard level in Padang. The figure shows that the mean hazard levels from both timedependent and independent models are similar, with the hazard level below $5 \mathrm{~m}$ for the 50 years simulation at a $2 \%$ probability (see Figure 15P-R). Thus, the maps show a similar hazard level between the time-dependent and the timeindependent models.

\section{Conclusions}

This study developed a time-dependent probabilistic tsunami hazard analysis for Western Sumatra. A new framework of the time-dependent PTHA adopting space and time interactions of earthquake ruptures was used to simulate future earthquake ruptures in the Sunda subduction zone. The Mentawai region of the Sunda subduction zone was considered as a case study to develop the tsunamigenic sources. Three important cities, namely Pariaman, Padang and Painan, were chosen as localities to assess the tsunami hazard using the time-dependent PTHA method. Another innovation in this study was to integrate stochastic tsunami simulation and the space-time interacting earthquake rupture modelling to develop time-dependent PTHA and compare it with a time-independent approach. The tsunamigenic source used to run the stochastic tsunami simulation adopts the earthquake supercyclic rupture areas of the Mentawai-Sunda zone in the last 450 years. Six magnitude scenarios,

M 7.75, M 8.0, M 8.25, M 8.5, M 8.75, and M 9.0, were considered for running the stochastic tsunami simulation. A total of 21 tsunami scenarios from 6 different magnitudes were adopted to generate the stochastic source models and then used to run the Monte Carlo tsunami simulations. Moreover, in the space-time interaction model, the BPT distribution and the spatial correlogram model were introduced to generate the time between failure states (inter-arrival time) and the stress interaction among the neighbouring zones within the tectonic region, respectively. To determine parameters in developing such models,

490 a Bayesian MCMC simulation was adopted. Subsequently, the final hazard curve and the hazard maps from the timedependent PTHA were obtained using the results from the stochastic tsunami simulation and the earthquake rupture modelling.

The earthquake rupture modelling results showed that the calibrated space-time interaction model successfully generates annual seismic moment release rates consistent with observations over the last 450 years. The time-dependent model also captured the uncertainty of future tsunamigenic events by producing a wide range of earthquake rupture catalogs. Comparing the mean hazard probabilities between the time-dependent and the time-independent approach indicated that the two approaches produce similar results. However, the time-dependent model produces 10-25\% higher hazard probability at a height level of $\leq 5 \mathrm{~m}$ for the short periods ( $\leq 20$ years). Therefore, the time-independent approach may underestimate the hazard level for a short-term period and hence, we recommend considering the time-dependent model for short-term hazard 500 assessment. In contrast, the time-independent model developed for a long-term (> 30 years) hazard assessment produced much higher hazard probabilities, by up to $\sim 30 \%$, than the time-dependent model. The time-independent model may be suitable to capture the worst-case scenario for future tsunami hazard and risk assessment analysis. 
Regionally, the PTHA assessment along the western coast of Sumatra showed that the southwestern part of Sumatra (Painan) located closer to the Mentawai-Sunda zone may experience more significant tsunami damage than the northwestern part (Padang and Pariaman). However, the tsunami hazards were still significant in those three cities, shown by $>5 \mathrm{~m}$ of tsunami height at the 50 years of simulation. The time-dependent PTHA approach may also produce more accurate tsunami hazard assessment results for short-term periods ( $\leq 50$ years). Therefore, it is essential to adopt the time-dependent PTHA to update the tsunami mitigation plans regionally because the Mentawai-Sunda zone is expected to have significant tsunamigenic events in the next few decades and currently, there has not been time-dependent PTHA work carried out there.

\section{Acknowledgements}

The authors gratefully acknowledge financial support from the University of Bristol through the 2017 Strategic Research Fund for the project "Modelling Seismic Risk Cascades: Towards Time-Dependent Earthquake Impact Assessment". This work was also supported by the Leverhulme Trust (RPG-2017-006) for the Global Earthquake Resilience for NaturalEngineering-Social Interacting Systems (GENESIS) project. M. J. W. received funding from the European Union's Horizon

5152020 research and innovation program under Grant Agreement Number 821115, Real-Time Earthquake Risk Reduction for a Resilient Europe (RISE). The bathymetry and elevation data for the Sumatra region were obtained from the GEBCO2014 database (http://www.gebco.net/data_and_products/gridded_bathymetry_data/) and the SRTM1 database (https://lta.cr.usgs.gov/SRTM1Arc), respectively.

\section{References}

520 Aki, K.: Maximum likelihood estimate of $\mathrm{b}$ in the formula $\log (\mathrm{N})=\mathrm{a}-\mathrm{bM}$ and its confidence limits. Bull. Earthq. Res. Inst. Univ. Tokyo, 43, 237-239, 1965.

Akinci, A., Galadini, F., Pantosti, D., Petersen, M., Malagnini, L., \& Perkins, D.: Effect of time dependence on probabilistic seismic-hazard maps and deaggregation for the Central Apennines, Italy. Bull. Seismol. Soc. Am., 99(2A), 585-610, 2009.

Akoh, R., Ishikawa, T., Kojima, T., Tomaru, M., \& Maeno, S.: High-resolution modelling of tsunami runup flooding: a case

525 study of flooding in Kamaishi city, Japan, induced by the 2011 Tohoku tsunami. Nat. Hazards Earth Syst. Sci., 17(11). 2017. Anagnos, T., \& Kiremidjian, A. S.: Stochastic time-predictable model for earthquake occurrences. Bull. Seismol. Soc. Am., 74(6), 2593-2611, 1984

Berryman, K. R., Cochran, U. A., Clark, K. J., Biasi, G. P., Langridge, R. M., \& Villamor, P.: Major earthquakes occur regularly on an isolated plate boundary fault. Science, 336(6089), 1690-1693, 2012.

530 Burroughs, S. M. \& Tebbens, S. F.: Power law scaling and probabilistic forecasting of tsunami runup heights, Pure Appl. Geophys. 162, 331-342, 2005.

Ceferino, L., Kiremidjian, A., \& Deierlein, G.: Probabilistic space-and time-interaction modelling of mainshock earthquake rupture occurrence. Bull. Seismol. Soc. Am., 110, 2498-2518, doi: 10.1785/0120180220, 2020.

Chib, S., \& Greenberg, E.: Understanding the Metropolis-Hastings algorithm. The Am. Stat., 49, 4, 327-335, 1995.

535 Convertito, V., Maercklin, N., Sharma, N., \& Zollo, A.: From induced seismicity to direct time-dependent seismic hazard. Bull. Seismol. Soc. Am., 102(6), 2563-2573, 2012.

De Risi, R., \& Goda, K.: Simulation-based probabilistic tsunami hazard analysis: empirical and robust hazard predictions. Pure Appl. Geophys., 174(8), 3083-3106, 2017. 
https://doi.org/10.5194/nhess-2022-59

Preprint. Discussion started: 24 February 2022

(c) Author(s) 2022. CC BY 4.0 License.

Field, E. H., Arrowsmith, R. J., Biasi, G. P., Bird, P., Dawson, T. E., Felzer, K. R., Jackson, D. D., Johnson, K. M., Jordan,

540 T. H., \& Madden, C.: Uniform California earthquake rupture forecast, version 3 (UCERF3) - the time-independent model. Bull. Seismol. Soc. Am., 104, 1122-1180., 2014.

Fukutani, Y., Moriguchi, S., Terada, K., \& Otake, Y.: Time-Dependent Probabilistic Tsunami Inundation Assessment Using Mode Decomposition to Assess Uncertainty for an Earthquake Scenario. Journal of Geophysical Research: Oceans, e2021JC017250, 2021.

545 GEBCO: Bathymetry and elevation data for the Sumatra region, available at: http://www.gebco.net/data_and_products/gridded_bathymetry_data/, last access: 1 December 2017.

Gelman, A., Stern, H. S., Carlin, J. B., Dunson, D. B., Vehtari, A., \& Rubin, D. B.: Bayesian data analysis. Chapman and Hall/CRC, 2013.

Goda, K., Yasuda, T., Mori, N., and Maruyama, T.: New scaling relationships of earthquake source parameters for

550 Stochastic Tsunami Simulation, Coast. Eng. J., 58, 1-40, https://doi.org/10.1142/S0578563416500108, 2016.

Goda, K.: Time-dependent probabilistic tsunami hazard analysis using stochastic source models. Stoch. Environ. Res. Risk Assess., 33, 341-358, 2019.

Goda, K., Yasuda, T., Mori, N., Muhammad, A., De Risi, R., and De Luca, F.: Uncertainty quantification of tsunami inundation in Kuroshio Town, Kochi Prefecture, Japan using the Nankai-Tonankai megathrust rupture scenarios. Nat.

555 Hazards Earth Syst. Sci., 20, 3039-3056, https://doi.org/10.5194/nhess-20-3039-2020, 2020.

Goto, C., Ogawa, Y., Shuto, N., and Imamura, F.: Numerical Method of Tsunami Simulation with the Leap-Frog Scheme, IOC Manual, UNESCO, Paris, France, 35, 1997.

Griffin, J. D., Pranantyo, I. R., Kongko, W., Haunan, A., Robiana, R., Miller, Davies, G., Horspool, N., Maemunah, I., Widjaja, W. B., Natawidjaja, D. H., and Latief, H.: Assessing tsunami hazard using heterogeneous slip models in the

560 Mentawai Islands, Indonesia, in: Geohazards in Indonesia: Earth Science for Disaster Risk Reduction, edited by: Cummins, P. R. and Meilano, I., Special Publications, Geological Society, London, UK, 441, https://doi.org/10.1144/SP441.3, 2016.

Gusman, A.R., Tanioka, Y., Kobayashi, T., Latief, H., and Pandoe, W.: Slip distribution of the 2007 Bengkulu earthquake inferred from tsunami waveforms and InSAR data. J. Geophys. Res. Solid Earth 115, B12316, doi:10.1029/2010JB007565, 2010.

565 Hanks, T. C., \& Kanamori, H.: A moment magnitude scale. J. Geophys. Res. Solid Earth, 84(B5), 2348-2350, 1979.

Hayes, G. P., Wald, D. J., and Johnson, R. L.: Slab1.0, a three-dimensional model of global subduction zone geometries, J. Geophys. Res.-Sol. Ea., 117, B01302, https://doi.org/10.1029/2011JB008524, 2012.

Herrendörfer, R., Van Dinther, Y., Gerya, T., \& Dalguer, L. A.: Earthquake supercycle in subduction zones controlled by the width of the seismogenic zone. Nat. Geo., 8(6), 471, 2015.

570 Horspool, N., Pranantyo, I., Griffin, J., Latief, H., Natawidjaja, D. H., Kongko, W., Cipta, A., Bustaman, B., Anugrah, S. D., and Thio, H. K.: A probabilistic tsunami hazard assessment for Indonesia. Nat. Hazards Earth Syst. Sci., 14, 3105-3122, doi:10.5194/nhess-14-3105-2014, 2014.

Ji, C.: Rupture process of the Sep 12, 2007 M 8.4 Sumatra earthquake: phase II. http://www.geol.ucsb.edu/faculty/ji/big_earthquakes/2007/09/sumatra_seismic.html, 2007.

575 Ji, C., \& Zeng, Y.: Preliminary result of the Sep 12, 2007 M 7.9 Kepulauan earthquake. http://earthquake.usgs.gov/earthquakes/eqinthenews/2007/us2007hec6/finite_fault.php, 2007.

Jin, R., Wang, S., Yan, F., \& Zhu, J.: Generating spatial correlated binary data through a copulas method. Sci. Res., 3(4), 206-212. http://doi.org/10.11648/j.sr.20150304.18, 2015.

Konca, A. O., Avouac, J.P., Sladen, A., Meltzner, A. J., Sieh, K., Fang, Fang, P., Li, Z., Galetzka, J., Genrich, J., Chlieh, M.,

580 Natawidjaja, D. H., Bock, Y., Fielding, E. J., Ji, C., and Helmberger, D. V.: Partial rupture of a locked patch of the Sumatra megathrust during the 2007 earthquake sequence. Nature, 456, 631-635. doi:10.1038/nature07572, 2008.

Kongko, W., \& Schlurmann, T.: The Java tsunami model: using highly-resolved data to model the past event and to estimate the future hazard. Coas. Eng. Proc., 1(32), 25, 2011.

Løvholt, F., Kühn, D., Bungum, H., Harbitz, C. B., \& Glimsdal, S.: Historical tsunamis and present tsunami hazard in 585 eastern Indonesia and the southern Philippines. J. Geophys. Res. Solid Earth, 117(B9), 2012.

Mai, P. M. and Beroza, G. C.: A spatial random field model to characterize complexity in earthquake slip, J. Geophys. Res.Sol. Ea., 107, ESE 10-1-ESE 10-21, https://doi.org/10.1029/2001JB000588, 2002 
https://doi.org/10.5194/nhess-2022-59

Preprint. Discussion started: 24 February 2022

(c) Author(s) 2022. CC BY 4.0 License.

Matthews, M. V., Ellsworth, W. L., \& Reasenberg, P. A.: A Brownian model for recurrent earthquakes. Bull. Seismol. Soc. Am., 92(6), 2233-2250, 2002.

590 Momeni, P., Goda, K., Heidarzadeh, M.: Stochastic analysis of tsunami hazard of the 1945 Makran subduction zone Mw 8.1-8.3 earthquakes, Geosciences, 10, 452, 10.3390/geosciences10110452, 2020.

Mori, N., Muhammad, A., Goda, K., Yasuda, T., and RuizAngulo, A.: Probabilistic tsunami hazard analysis of the Pacific Coast of Mexico: case study based on the 1995 Colima earthquake tsunami, Front. Built Environ., 3, 1-16, https://doi.org/10.3389/fbuil.2017.00034, 2017.

595 Muhammad, A., Goda, K., and Alexander, N.: Tsunami hazard analysis of future megathrust Sumatra earthquakes in Padang, Indonesia using stochastic tsunami simulation, Front. Built Environ., 2, 33, 1-19, https://doi.org/10.3389/fbuil.2016.00033, 2016.

Muhammad, A., Goda, K., Alexander, N. A., Kongko, W., \& Muhari, A.: Tsunami evacuation plans for future megathrust earthquakes in Padang, Indonesia, considering stochastic earthquake scenarios. Nat. Hazards Earth Syst. Sci., 17, 2245-2270, 600 doi:10.5194/nhess-17-2245-2017, 2017.

Muhammad, A., \& Goda, K.: Impact of earthquake source complexity and land elevation data resolution on tsunami hazard assessment and fatality estimation. Comput. Geosci., 112, 83-100, 2018.

Muhammad, A., De Risi, R., De Luca, F., Mori, N., Yasuda, T., \& Goda, K.: Are current tsunami evacuation approaches safe enough?. Stoch. Environ. Res. Risk Assess., 35(4), 759-779, 2021.

605 Natawidjaja, D. H., Sieh, K., Chlieh, M., Galetzka, J., Suwargadi, B. W., Cheng, H., Edwards, R. L., Avouac, J. P., and Ward, S. N.: Source parameters of the great Sumatran megathrust earthquakes of 1797 and 1833 inferred from coral microatolls, J. Geophys. Res.-Sol. Ea., 111, B06403, https://doi.org/10.1029/2005JB004025, 2006.

Ogata, Y.: Estimating the hazard of rupture using uncertain occurrence times of paleoearthquakes. J. Geophys. Res. Solid Earth, 104(B8), 17995-18014, 1999.

610 Okada, Y.: Surface deformation due to shear and tensile faults in a half-space. B. Seismol. Soc. Am., 75, 1135-1154, 1985.

Orfanogiannaki, K., \& Papadopoulos, G. A.: Conditional probability approach of the assessment of tsunami potential: Application in three tsunamigenic regions of the Pacific Ocean. Pure Appl. Geophys., 164 (2-3), 593-603, 2007.

Park, H., Cox, D.T., Alam, M.S., and Barbosa, A.R.: Probabilistic seismic and tsunami hazard analysis conditioned on a megathrust rupture of the Cascadia subduction zone. Front. Built Environ., 3, 32. doi:10.3389/fbuil.2017.00032, 2017.

615 Parsons, T., \& Geist, E. L.: Tsunami probability in the Caribbean region. Pure Appl. Geophys., 165, 2089-2116, 2009.

Philibosian, B., Sieh, K., Avouac, J. P., Natawidjaja, D. H., Chiang, H., Wu, C., Perfettini, H., Shen, C. C., Daryono, M. R., and Suwargadi, B. W.: Rupture and variable coupling behavior of the Mentawai segment of the Sunda megathrust during the super cycle culmination of 1797 to 1833, J. Geophys. Res.-Sol. Ea., 119, 7258-7287, https://doi.org/10.1002/2014JB011200, 2014.

620 Philibosian, B., Sieh, K., Avouac, J. P., Natawidjaja, D. H., Chiang, H. W., Wu, C. C., \& Lu, Y.: Earthquake supercycles on the Mentawai segment of the Sunda megathrust in the seventeenth century and earlier. J. Geophys. Res. Solid Earth, 122(1), 642-676, 2017.

Pregnolato, M., Ford, A., Wilkinson, S. M., \& Dawson, R. J.: The impact of flooding on road transport: A depth-disruption function. Transp Res D Transp Environ., 55, 67-81, 2017.

625 Reid, H. F.: The elastic-rebound theory of earthquakes. Bull. Dept. Geo., 6, 413-444., 1911.

Rossetto, T., Peiris, N., Pomonis, A. et al.: The Indian Ocean tsunami of December 26, 2004: observations in Sri Lanka and Thailand. Nat. Haz., 42: 105. doi:10.1007/s11069-006-9064-3, 2007.

Raby, A., Macabuag, J., Pomonis, A., Wilkinsond, S., and Rossetto, T.: Implications of the 2011 Great East Japan Tsunami on sea defence design. Int. J. Disaster Risk Reduct., 14, 332-336. doi:10.1016/j.ijdrr.2015.08.009, 2015.

630 Satake, K., Nishimura, Y., Putra, P. S., Gusman, A. R., Sunendar, H., Fujii, Y., Sunendar, H., Latief, H., and Yulianto, E.: Tsunami source of the 2010 Mentawai, Indonesia earthquake inferred from tsunami field survey and waveform modeling, Pure Appl. Geophys., 170, 1567-1582, https://doi.org/10.1007/s00024-012-0536-y, 2013.

Selvan, S. C., \& Kankara, R. S.: Tsunami model simulation for 26 December 2004 and its effect on Koodankulam region of Tamil Nadu Coast. Int. j. ocean clim. syst., 7(2), 62-69, 2016.

635 Sherlock, C., \& Roberts, G.: Optimal scaling of the random walk Metropolis on elliptically symmetric unimodal targets. Bernoulli, 15(3), 774-798, 2009. 
Sieh, K., Natawidjaja, D. H., Meltzner, A. J., Shen, C. C., Cheng, H., Li, K. S., Suwargadi, B. W., Galetzka, J., Philibosian, B., and Edwards, R. L.: Earthquake super cycles inferred from sea-level changes recorded in the corals of West Sumatra, Science, 322, 1674-1678, https://doi.org/10.1126/science.1163589, 2008.

640 Tanioka, Y. and Satake, K.: Tsunami generation by horizontal displacement of ocean bottom, Geophys. Res. Lett., 23, 861864, 1996.

Tinti, S., Armigliato, A., Tonini, R., Maramai, A., \& Graziani, L.: Assessing the hazard related to tsunamis of tectonic origin: a hybrid statistical-deterministic method applied to southern Italy coasts. ISET J. of Earth. Tech., 42 (4), 189-201, 2005.

645 United States Geological Survey (USGS).: Latest earthquakes. http://earthquake.usgs.gov/earthquakes/map/, last access: 1 December 2020.

Wallace, L M., Spahr C. Webb, Yoshihiro Ito, Kimihiro Mochizuki, Ryota Hino, Stuart Henrys, Susan Y. Schwartz, and Anne F. Sheehan. "Slow slip near the trench at the Hikurangi subduction zone, New Zealand." Science 352, no. 6286 (2016): 701-704, 2016.

650 Yue, H., Lay, T., Rivera, L., Bai, Y., Yamazaki, Y., Cheung, K. F., Hill, E. M., Sieh, K., Kongko, W., and Muhari, A.: Rupture process of the $2010 \mathrm{Mw} 7.8$ Mentawai tsunami earthquake from joint inversion of near-field hr-GPS and teleseismic body wave recordings constrained by tsunami observations, J. Geophys. Res.-Sol.Ea., 119, 5574-5593, https://doi.org/10.1002/2014JB011082, 2014.

Zhuang, J., D. Harte, M.J. Werner, S. Hainzl, and Zhou, S.: Basic models of seismicity: temporal models, Com. Online Res. 
https://doi.org/10.5194/nhess-2022-59

Preprint. Discussion started: 24 February 2022

(c) Author(s) 2022. CC BY 4.0 License.

Table 1 Past significant tsunamigenic events in the Mentawai-Sunda subduction zone over the last 450 years

\begin{tabular}{|c|c|c|c|c|}
\hline No. & Year & Magnitude (M) & Recorded tsunami height & References \\
\hline 1 & 1597 & 8.4 & N/A & Sieh et al. (2008); Philibosian et al. (2017) \\
\hline 2 & 1613 & 8.4 & N/A & Sieh et al. (2008); Philibosian et al. (2017) \\
\hline 3 & 1631 & 8.3 & N/A & Sieh et al. (2008); Philibosian et al. (2017) \\
\hline 4 & 1658 & 8.4 & N/A & Sieh et al. (2008); Philibosian et al. (2017) \\
\hline 5 & 1703 & 8.6 & N/A & Sieh et al. (2008); Philibosian et al. (2017) \\
\hline 6 & 1797 & 8.8 & $\begin{array}{l}\text { 5-7 } \mathrm{m} \text { in Padang and } \\
\text { Bengkulu }\end{array}$ & $\begin{array}{l}\text { Natawaidjaja et al. (2006); Shieh et al. (2008); Philibosian et al. } \\
\qquad(2014,2017)\end{array}$ \\
\hline 7 & 1833 & 8.9 & $\begin{array}{l}\text { 5-7 } \mathrm{m} \text { in Padang, } \\
\text { Bengkulu and Manna }\end{array}$ & $\begin{array}{c}\text { Natawaidjaja et al. (2006, 2007); Shieh et al. (2008); Philibosian et } \\
\text { al. }(2014,2017)\end{array}$ \\
\hline 8 & $2007 \mathrm{a}$ & 8.4 & No significant tsunami & Ji (2007); Konca et al. (2008); Gusman et al. (2010) \\
\hline 9 & $2007 b$ & 7.9 & No significant tsunami & Ji and Zheng (2007); Konca et al. (2008) \\
\hline 10 & 2010 & 7.8 & $\begin{array}{l}\text { 3-5 } \mathrm{m} \text { in the coastal areas } \\
\text { of Pagai Islands }\end{array}$ & Hayes et al. (2012); Satake et al. (2013); Yue et al. (2014) \\
\hline
\end{tabular}

Table 2. Maximum and minimum lengths of each magnitude scenario

\section{Fault length $(\mathbf{k m})$}

Magnitude Minimum Maximum

$\begin{array}{ccc} & \mathrm{m} & \mathrm{m} \\ 7.75 & 60 & 100 \\ 8.00 & 160 & 200 \\ 8.25 & 260 & 300 \\ 8.50 & 360 & 400 \\ 8.75 & 460 & 500 \\ 9.00 & 560 & 600\end{array}$


https://doi.org/10.5194/nhess-2022-59

Preprint. Discussion started: 24 February 2022

(C) Author(s) 2022. CC BY 4.0 License.

Table 3. Bayesian parameter estimates of marginal BPT distributions of ruptures and spatial correlation.

\begin{tabular}{|c|c|c|c|}
\hline \multirow{2}{*}{ Segment } & \multicolumn{3}{|c|}{ Maximum a posteriori (MAP) } \\
\cline { 2 - 3 } & $\mu$ (years) & $\alpha$ & $\gamma(\mathrm{km})$ \\
\hline 1 & 173 & 0.62 & \multirow{2}{*}{} \\
\hline 2 & 36 & 1.05 & \multirow{2}{*}{500} \\
\hline 3 & 36 & 1.16 & 0.96 \\
\hline 4 & 44 & 0.62 & \\
\hline 5 & 121 & 0.66 & \\
\hline 6 & 147 & \\
\hline
\end{tabular}


https://doi.org/10.5194/nhess-2022-59

Preprint. Discussion started: 24 February 2022

(c) Author(s) 2022. CC BY 4.0 License.

(c) (1)
Natural Hazards and Earth System Sciences

Discussions
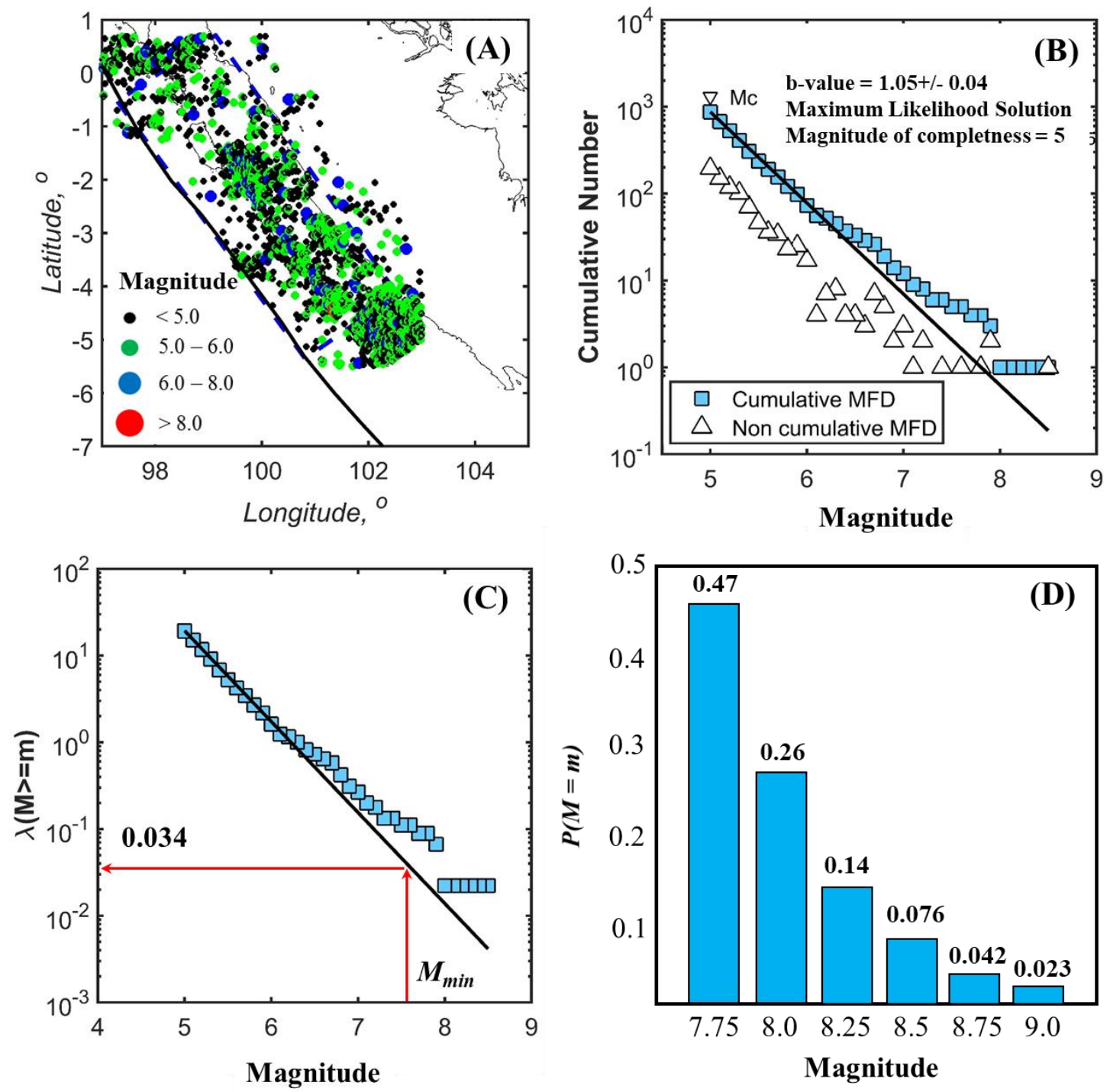

Figure 1. (A) Earthquake epicentres in the Mentawai-Sunda zone from 1970 to 2015 with magnitudes $>5.0$. (B) $b$ value estimation. (C) Mean annual rate of earthquake occurrence. (D) Discretized probability distribution of magnitude. 


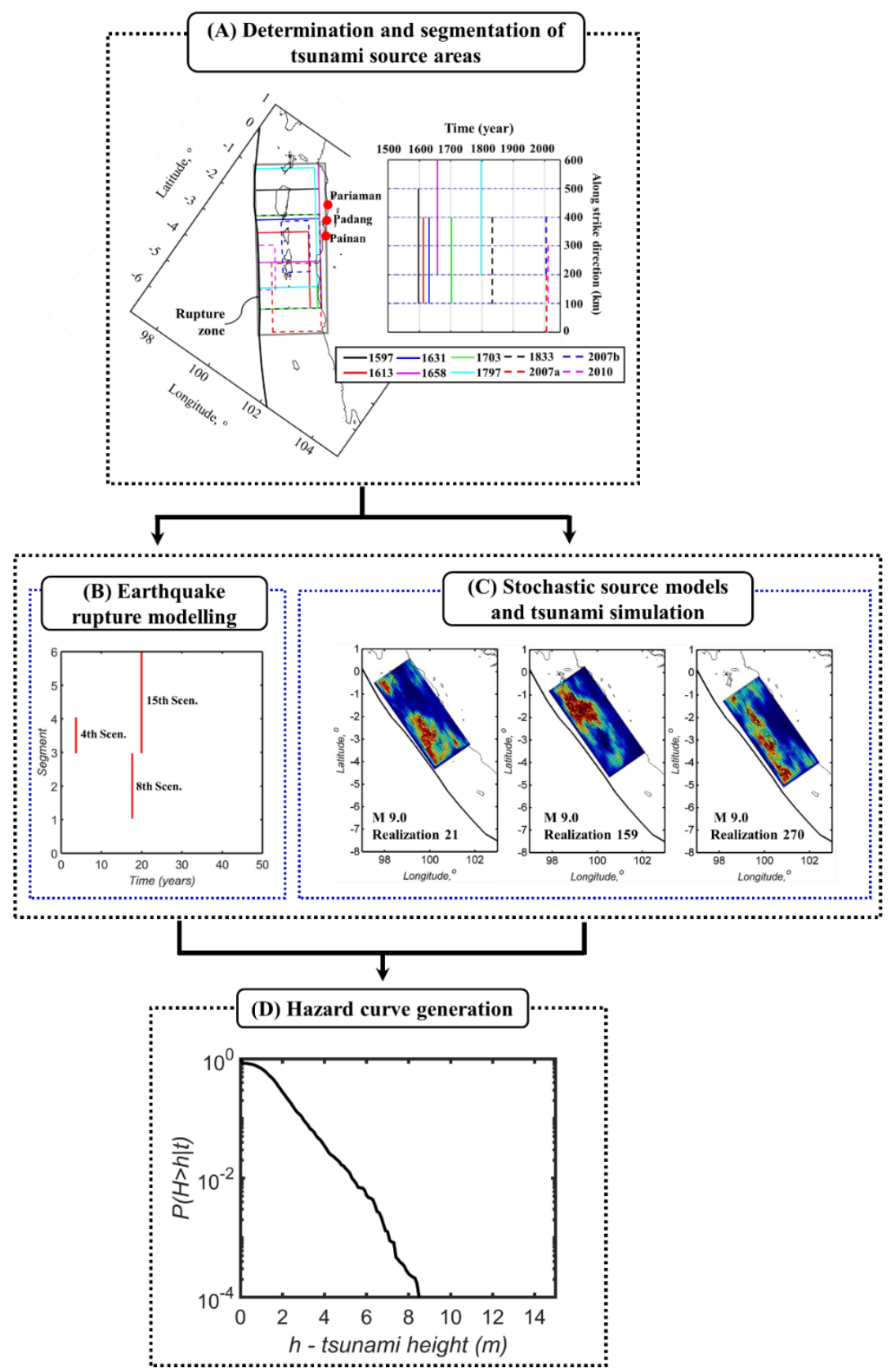

Figure 2. Time-dependent PTHA framework. (A) Determination and segmentation of tsunami source areas based on the supercyclic tsunamigenic earthquakes in the Mentawai-Sunda zone. (B) An example of one simulation of earthquake rupture modelling. The $4^{\text {th }}, 8^{\text {th }}$, and $15^{\text {th }}$ scenarios refer to different rupture scenarios. (C) Stochastic tsunami source simulation (stochastic earthquake slip models). (D) Generation of hazard curves. 


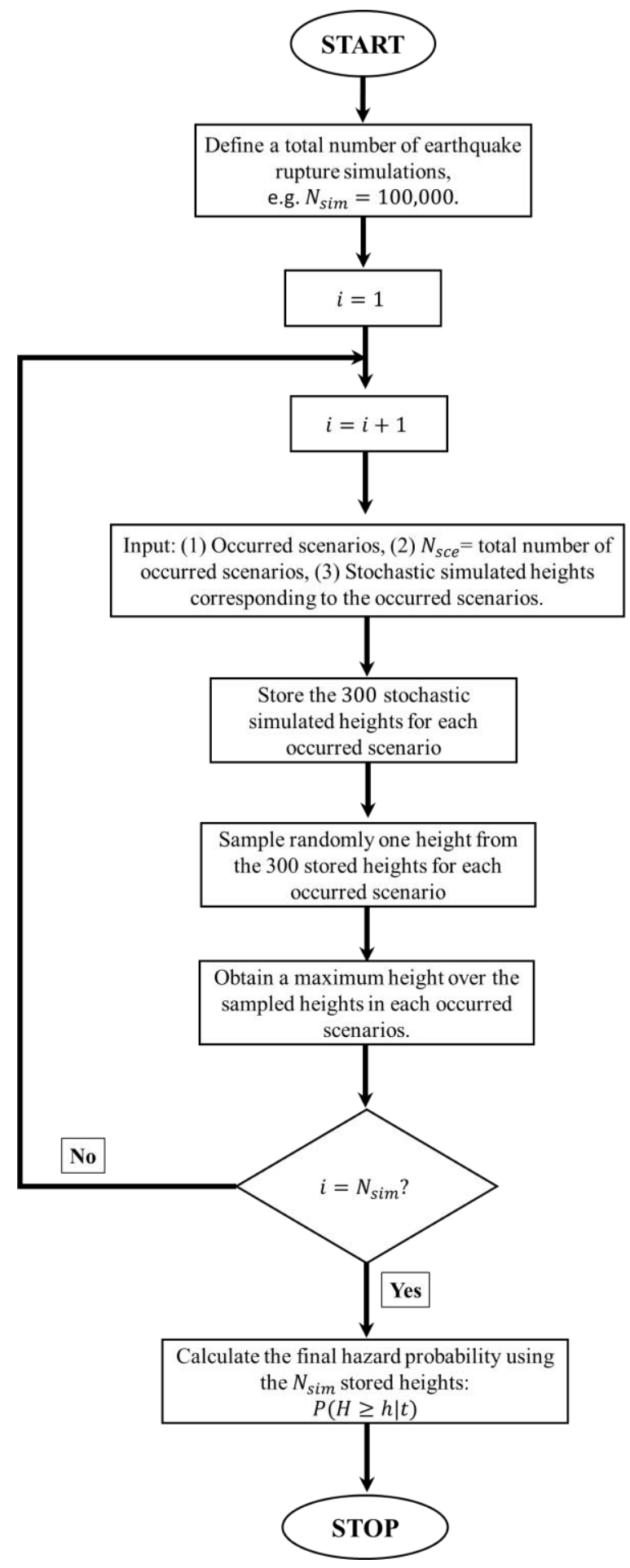

Figure 3 Procedure to generate the time-dependent mean hazard curve. 

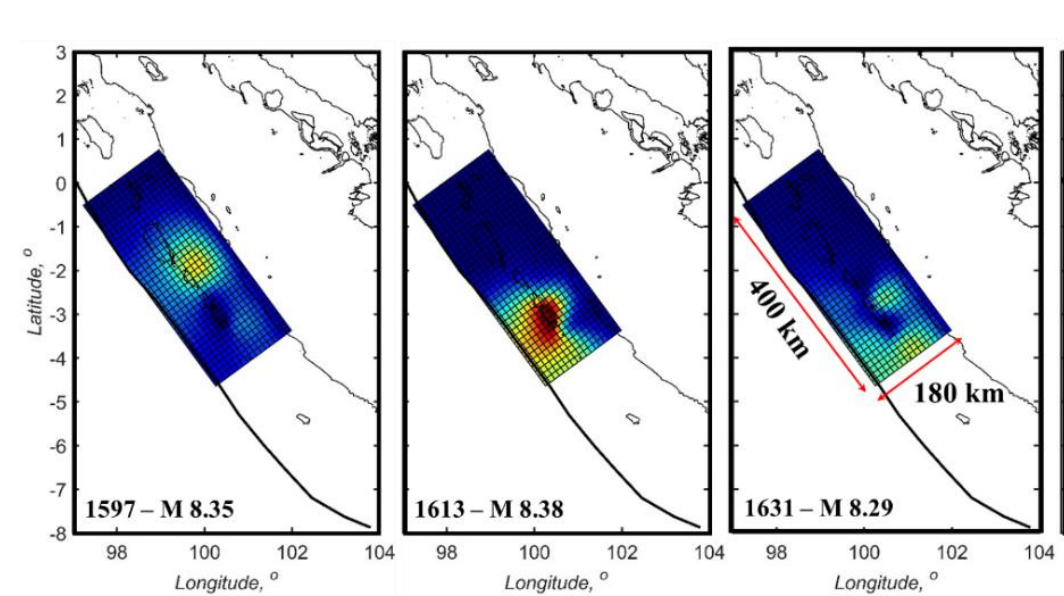

Slip (m)
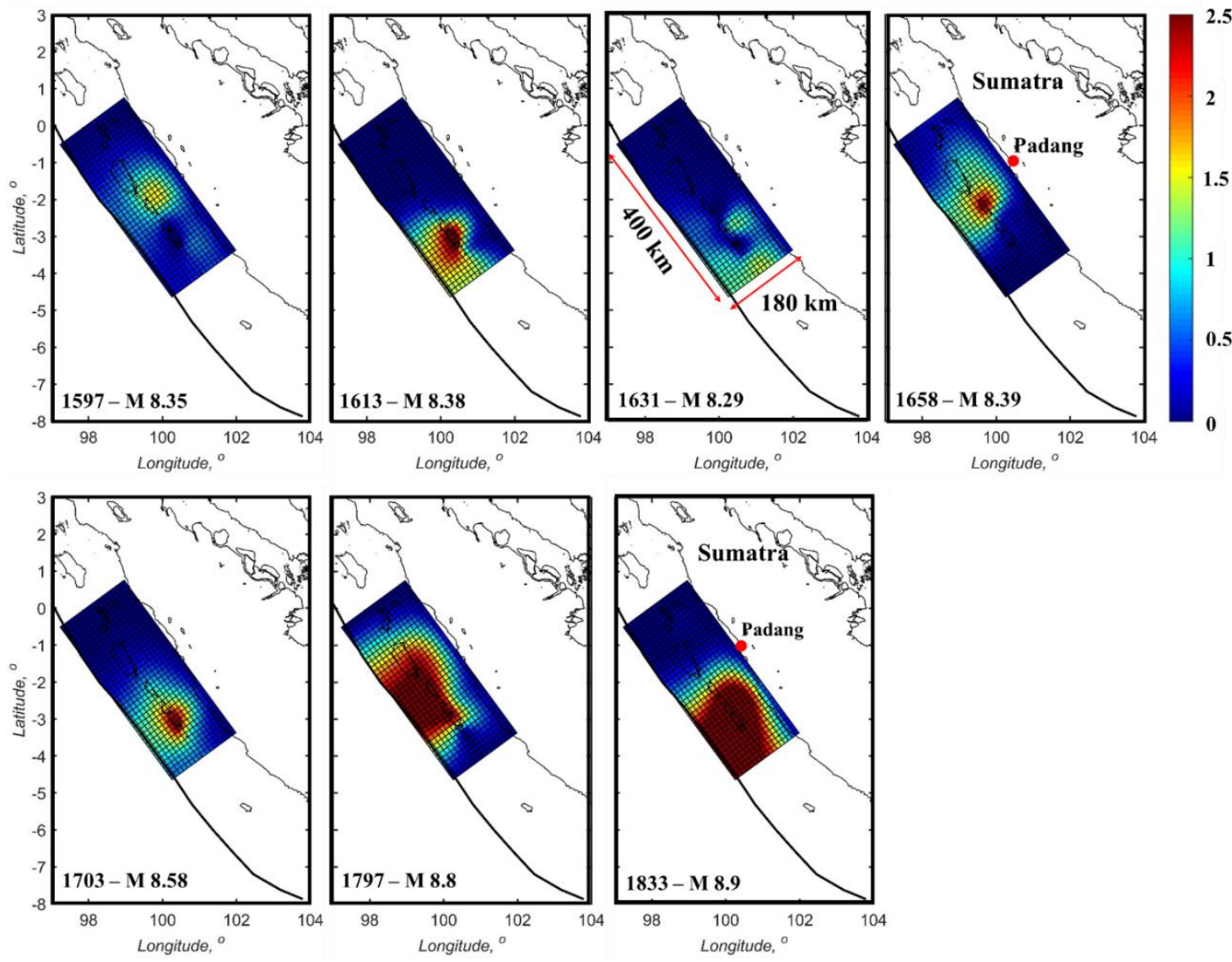

Figure 4. Source models of tsunamigenic earthquakes between the $16^{\text {th }}$ and $19^{\text {th }}$ centuries inverted from paleogeodetic measurements by Philibosian et al. (2017). 
https://doi.org/10.5194/nhess-2022-59

Preprint. Discussion started: 24 February 2022

(c) Author(s) 2022. CC BY 4.0 License.

(c) (i)

\section{Natural Hazards and Earth System \\ Sciences \\ Discussions}

Slip (m)
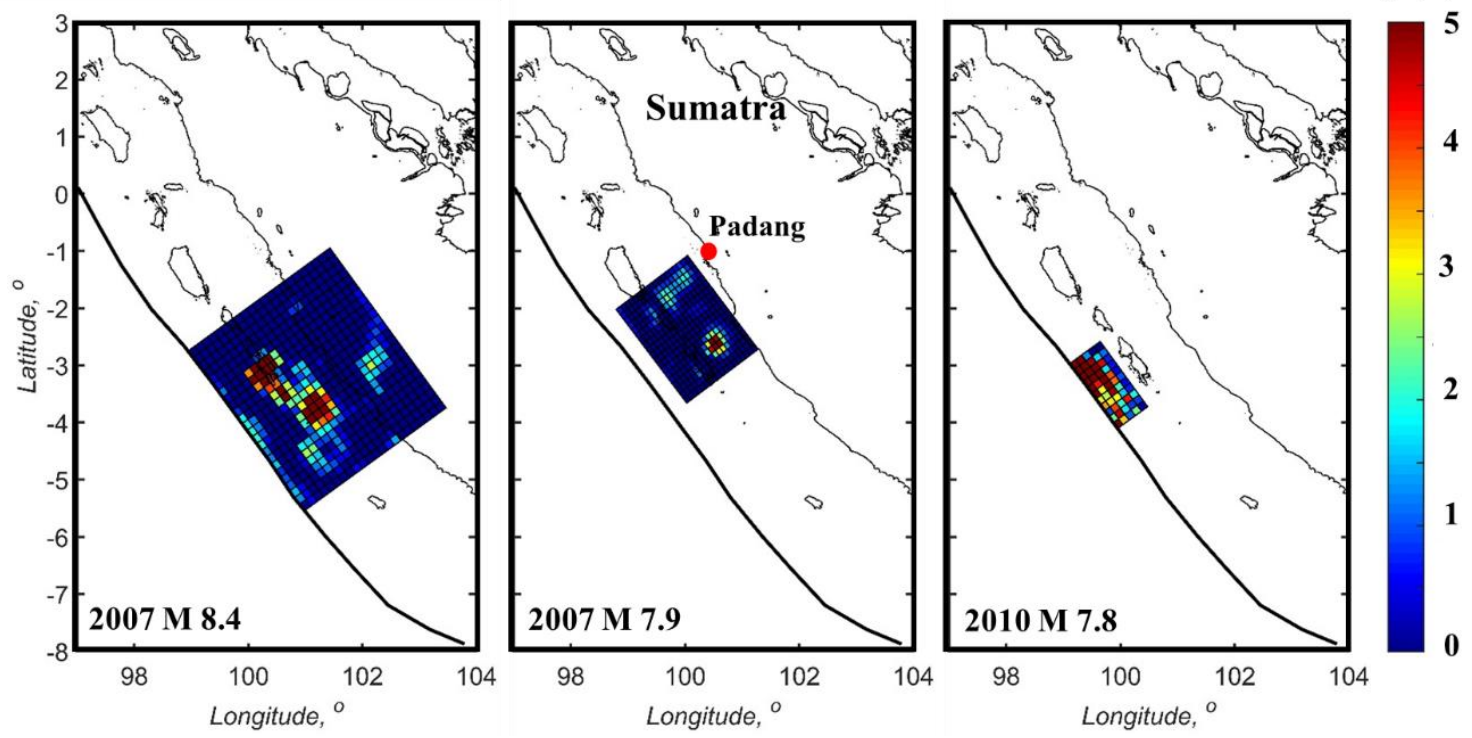

Figure 5. Source models of recent earthquakes that are constrained by geodetic measurements and seismological data (Konca et al., 2008; Yue et al., 2014). 
https://doi.org/10.5194/nhess-2022-59

Preprint. Discussion started: 24 February 2022

(c) Author(s) 2022. CC BY 4.0 License.

(A)

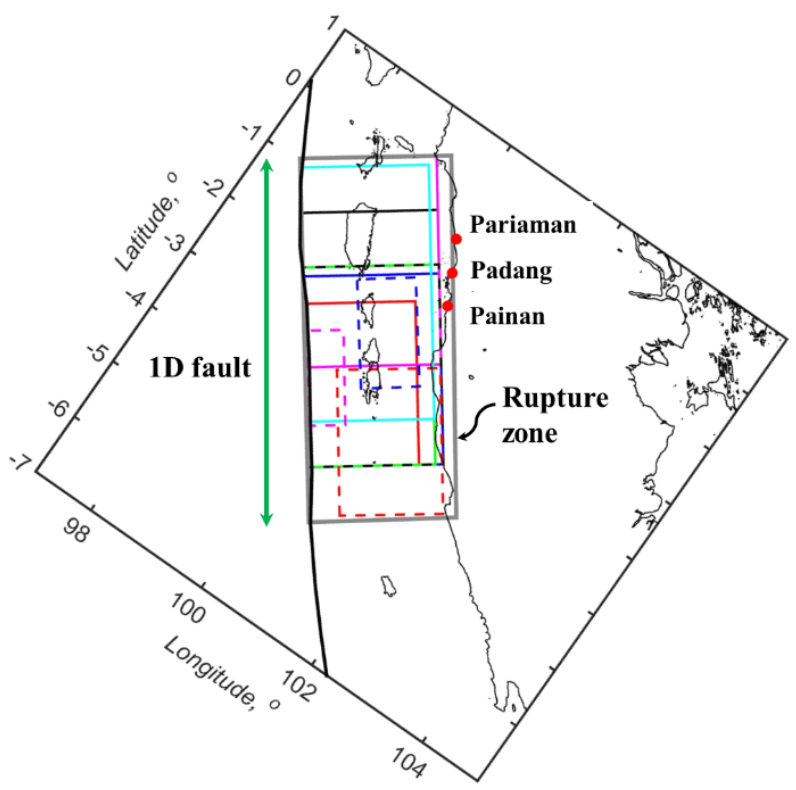

(B)
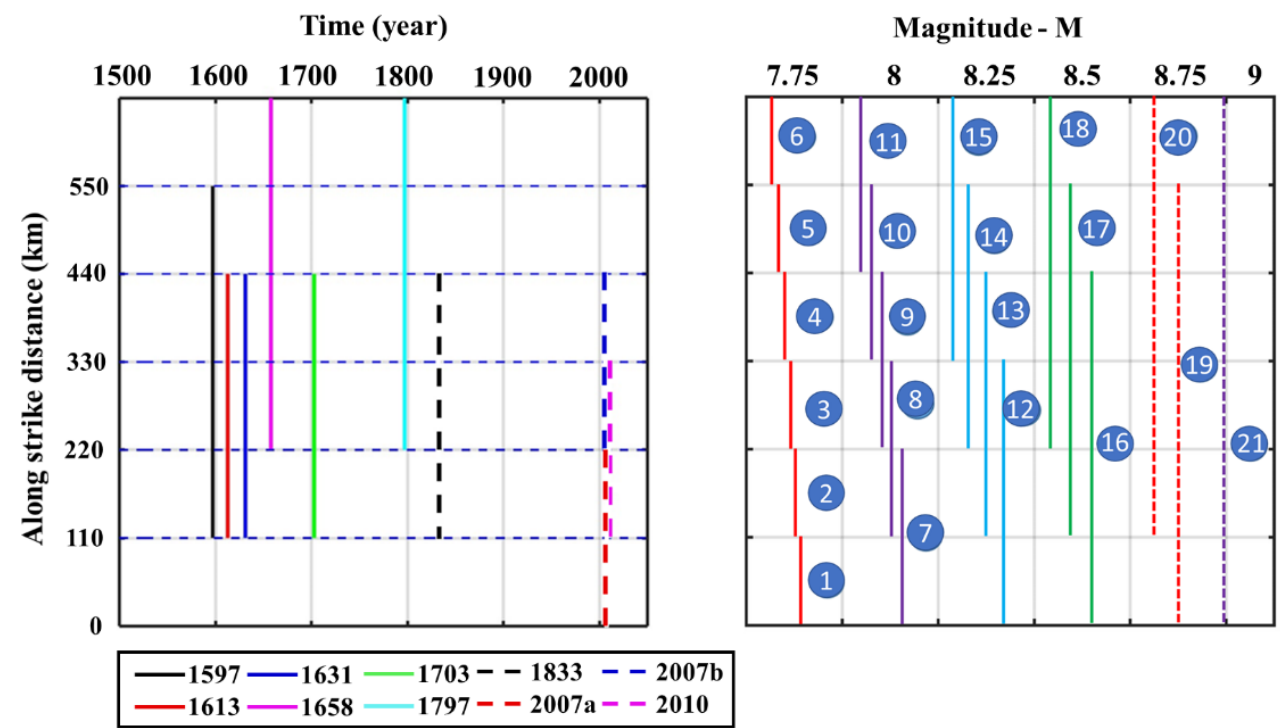

Figure 6. (A) One-dimensional (1D) representation of the fault from effective along-strike lengths of the earthquake source models from past tsunamigenic events in the Mentawai-Sunda zone. It covers the three study areas: Pariaman, Padang, and Painan. (B) Discretization of tsunamigenic sources. 


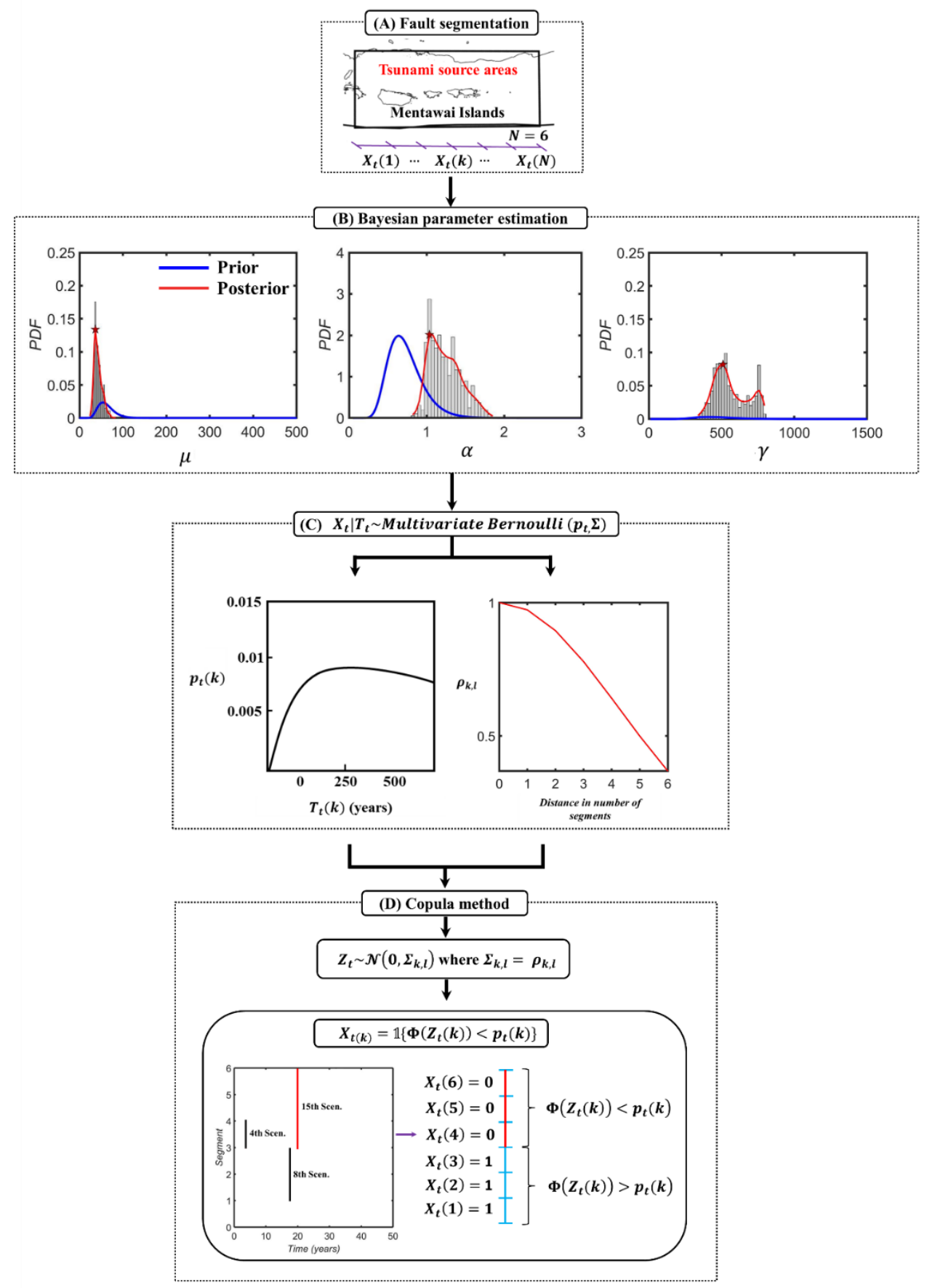

695 Figure 7. Procedures for modelling spatially-correlated earthquake ruptures on segments with marginal Brownian Passage Time (BPT) probability distributions. 

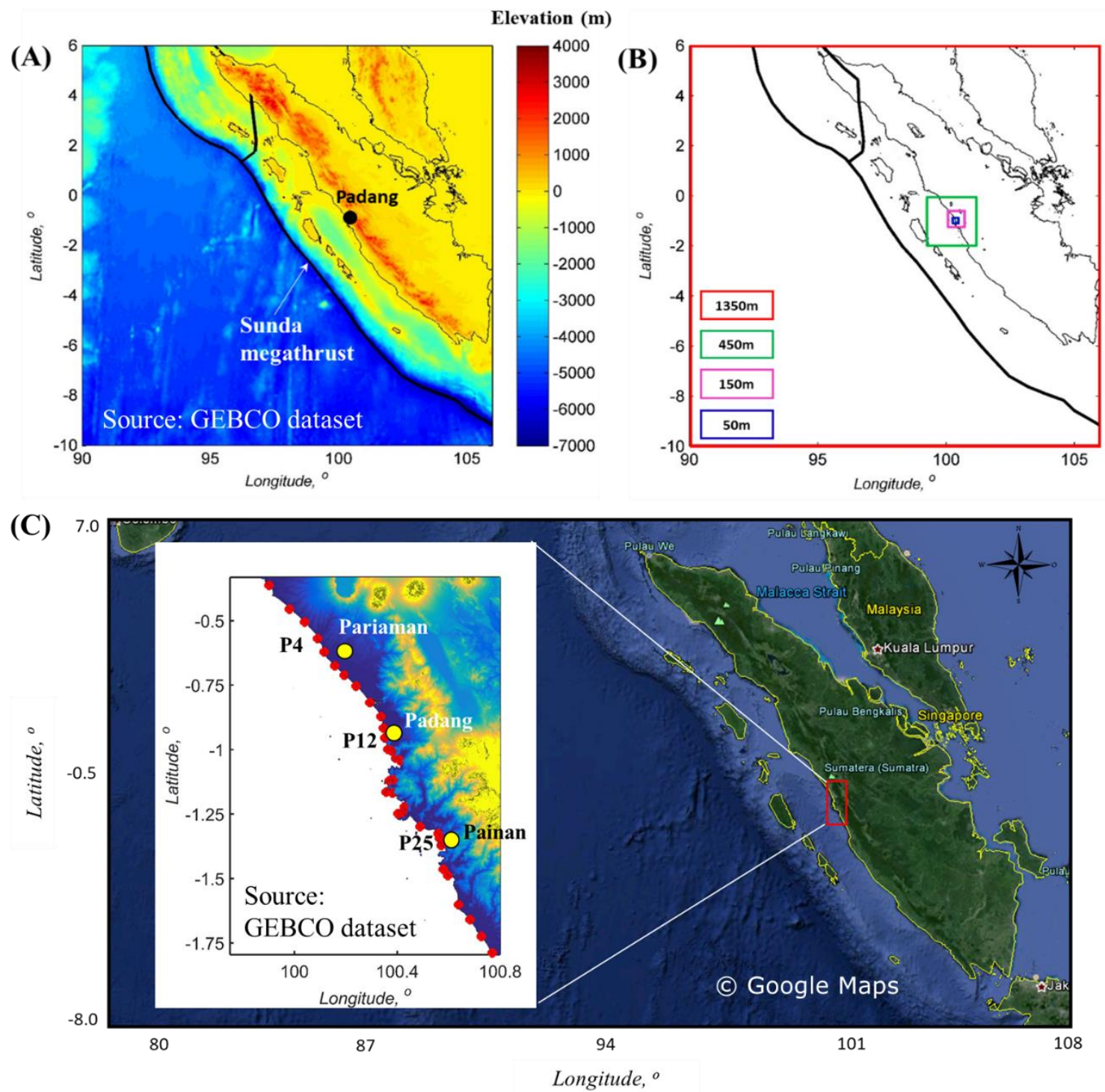

Figure 8. (A). Digital Elevation Model and bathymetry for the Mentawai-Sunda region (GEBCO, 2017). (B) Nested grids used for tsunami simulation in Padang. (C) Detailed study areas where the simulated tsunami heights are computed (Source of base map: (C) Google Maps). 
https://doi.org/10.5194/nhess-2022-59

Preprint. Discussion started: 24 February 2022

(c) Author(s) 2022. CC BY 4.0 License.
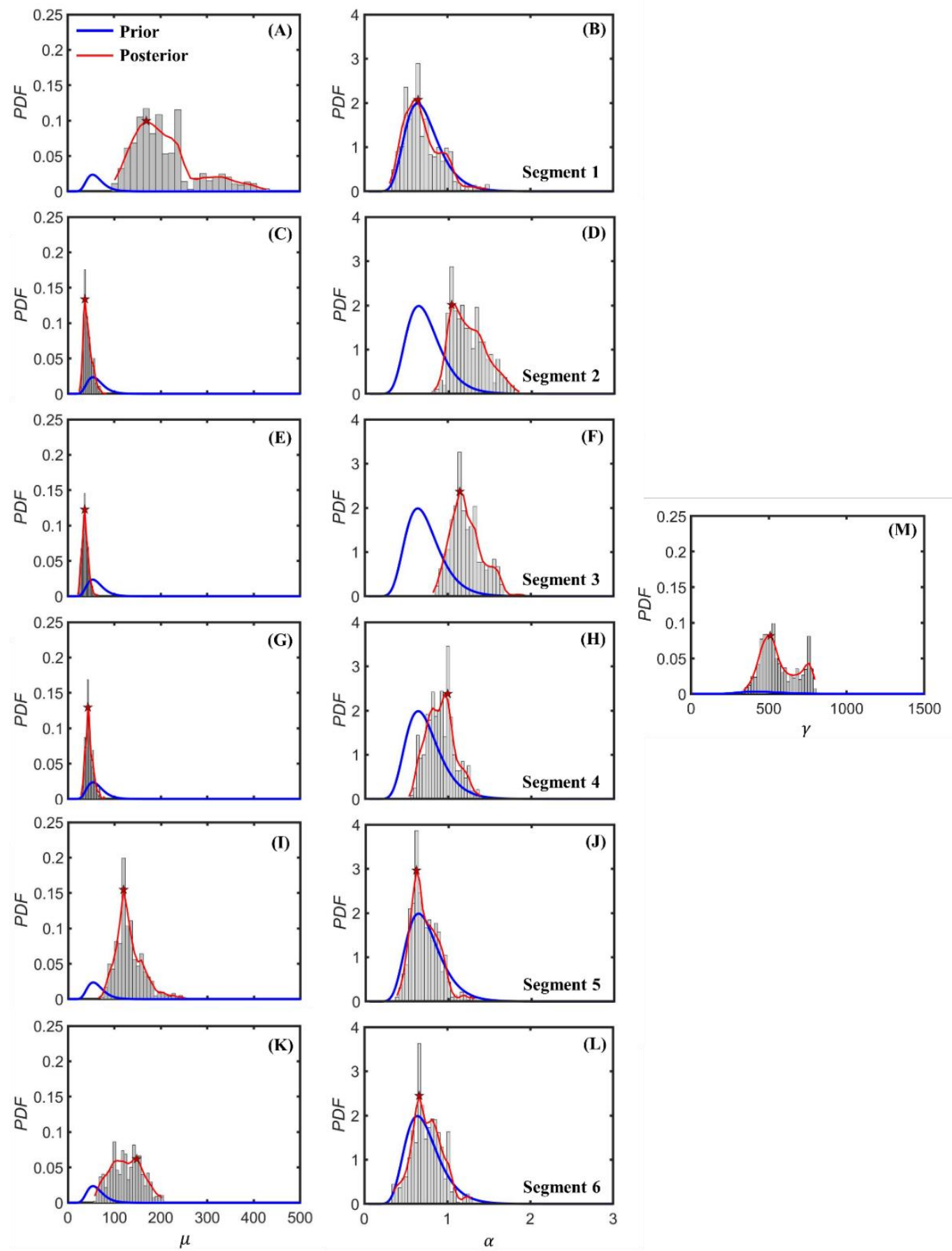

Figure 9. Bayesian parameter estimation of $\mu, \alpha$, and $\gamma$ for all segments. The posterior histogram is calculated from the simulation, whilst the blue and the red lines represent the PDF of the prior and the estimated posterior. 


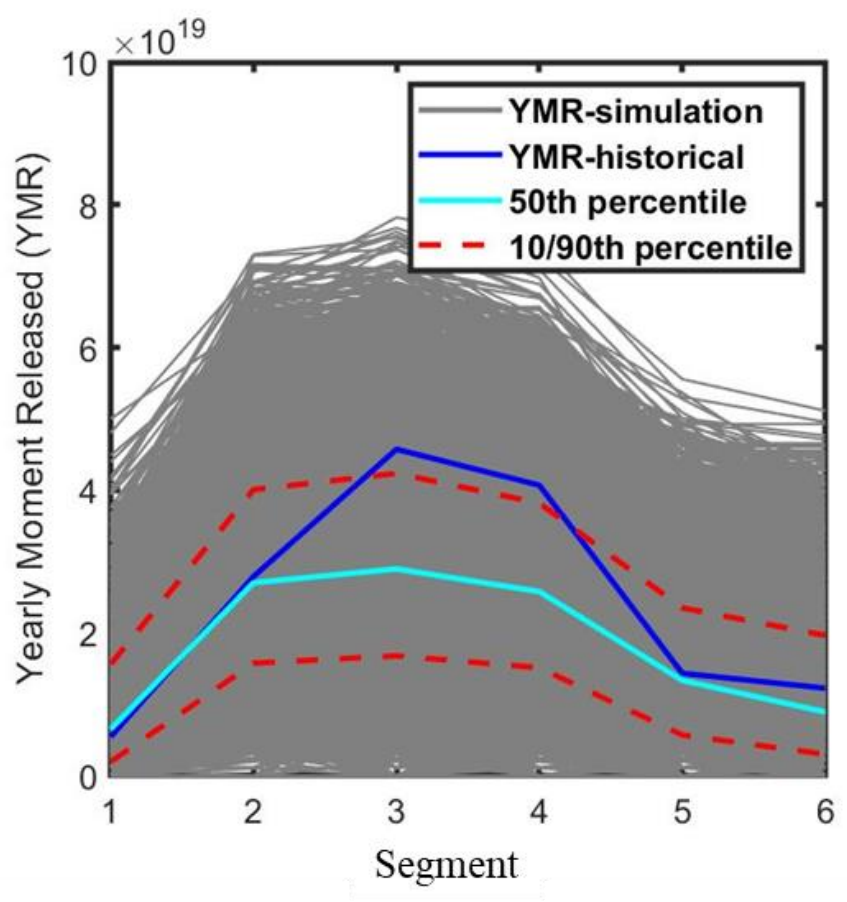

710 Figure 10. Comparison of observed and simulated annual seismic moment release. The red lines represent the $10^{\text {th }}$ and the $90^{\text {th }}$ percentile of the simulated annual moment released, whilst the cyan color shows the $\mathbf{5 0}^{\text {th }}$ percentile of the simulation annual moment released. 
https://doi.org/10.5194/nhess-2022-59

Preprint. Discussion started: 24 February 2022

(c) Author(s) 2022. CC BY 4.0 License.
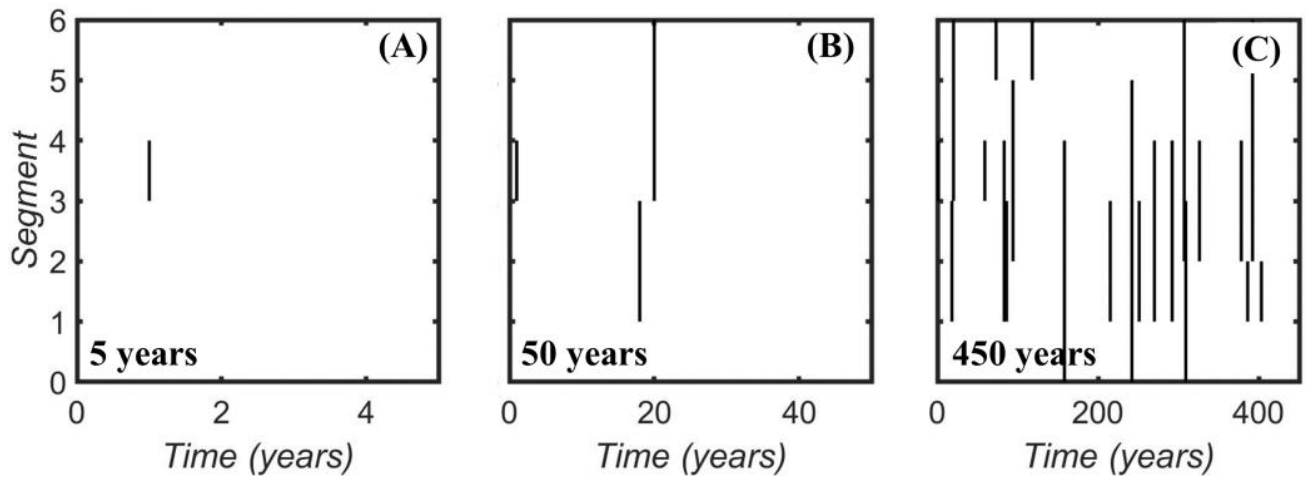

715 Figure 11. Results of earthquake rupture simulations for three different periods, i.e. 5 years (A), 50 years (B), and 450 years (C) from one simulation catalog (number 152). 

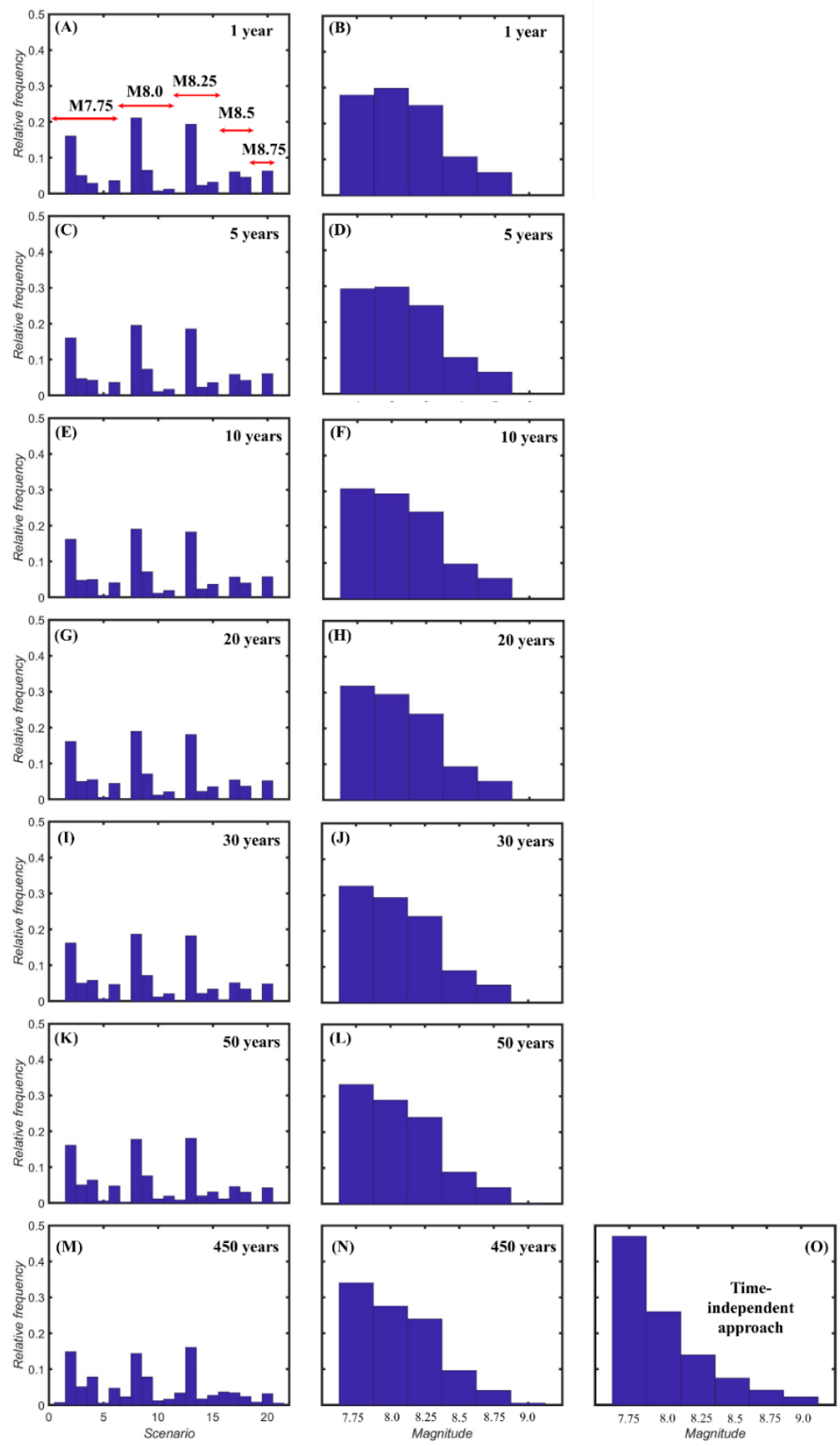

Figure 12. Percentage of occurrence of each scenario (left panel) and magnitude (central panel) produced from the rupture simulation over seven periods: 1 year (A and B), 5 years $(C$ and D), 10 years $(E$ and $F), 20$ years $(G$ and $H), 30$ years $(I$ and $J), 50$ years $(K$ and $L)$, and 450 years $(M$ and $N)$. For comparison, the probability values of each magnitude from the time-independent approach are plotted in $(\mathrm{O})$. 

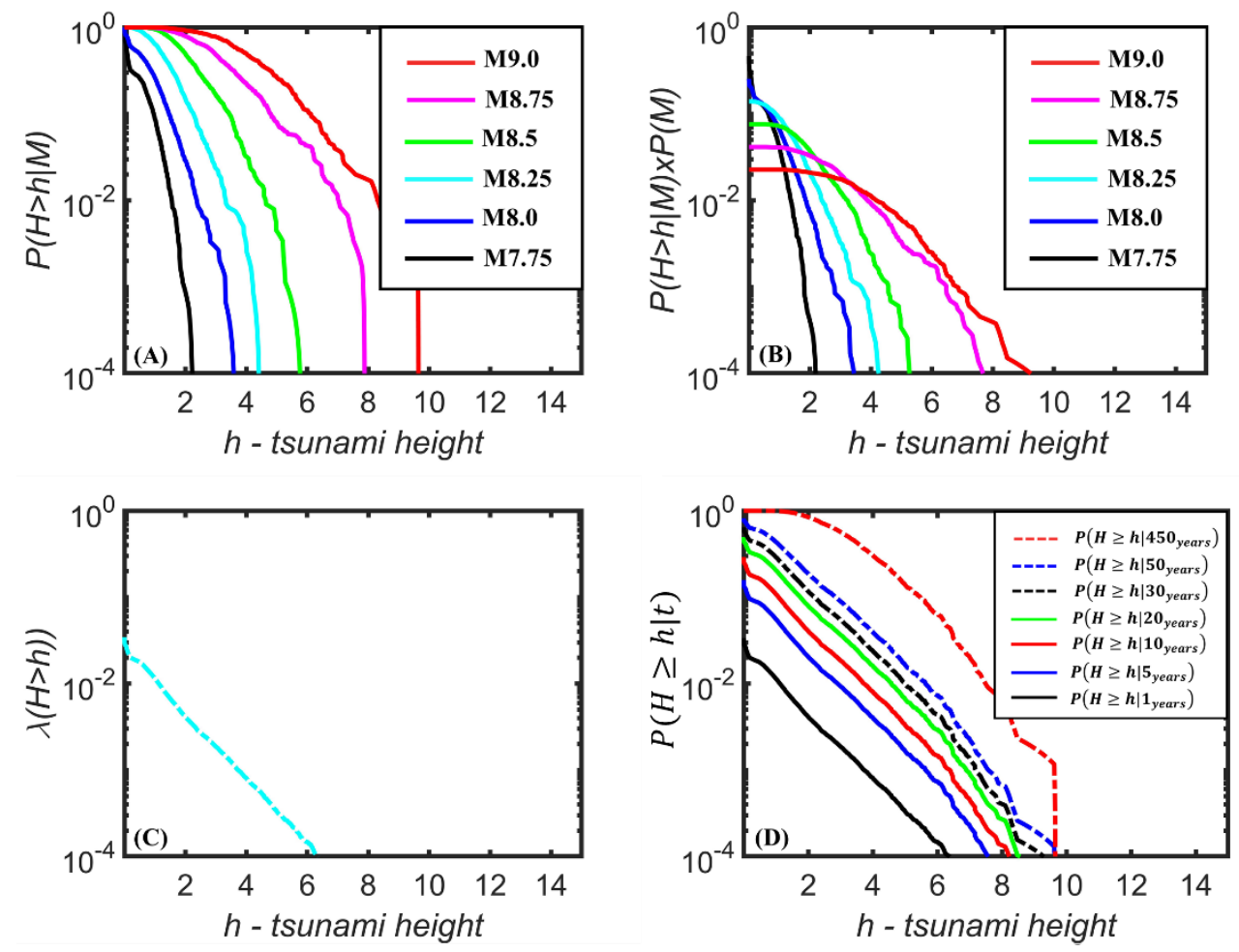

725 Figure 13. Development of final hazard curve for the time-independent model: (A) conditional hazard curve of each magnitude, (B) the conditioned hazard curve weighted by the probability values obtained from the discretized Gutenberg-Richter relationship, (C) mean annual hazard rate, and (D) the final hazard curve conditioned to considered periods. 

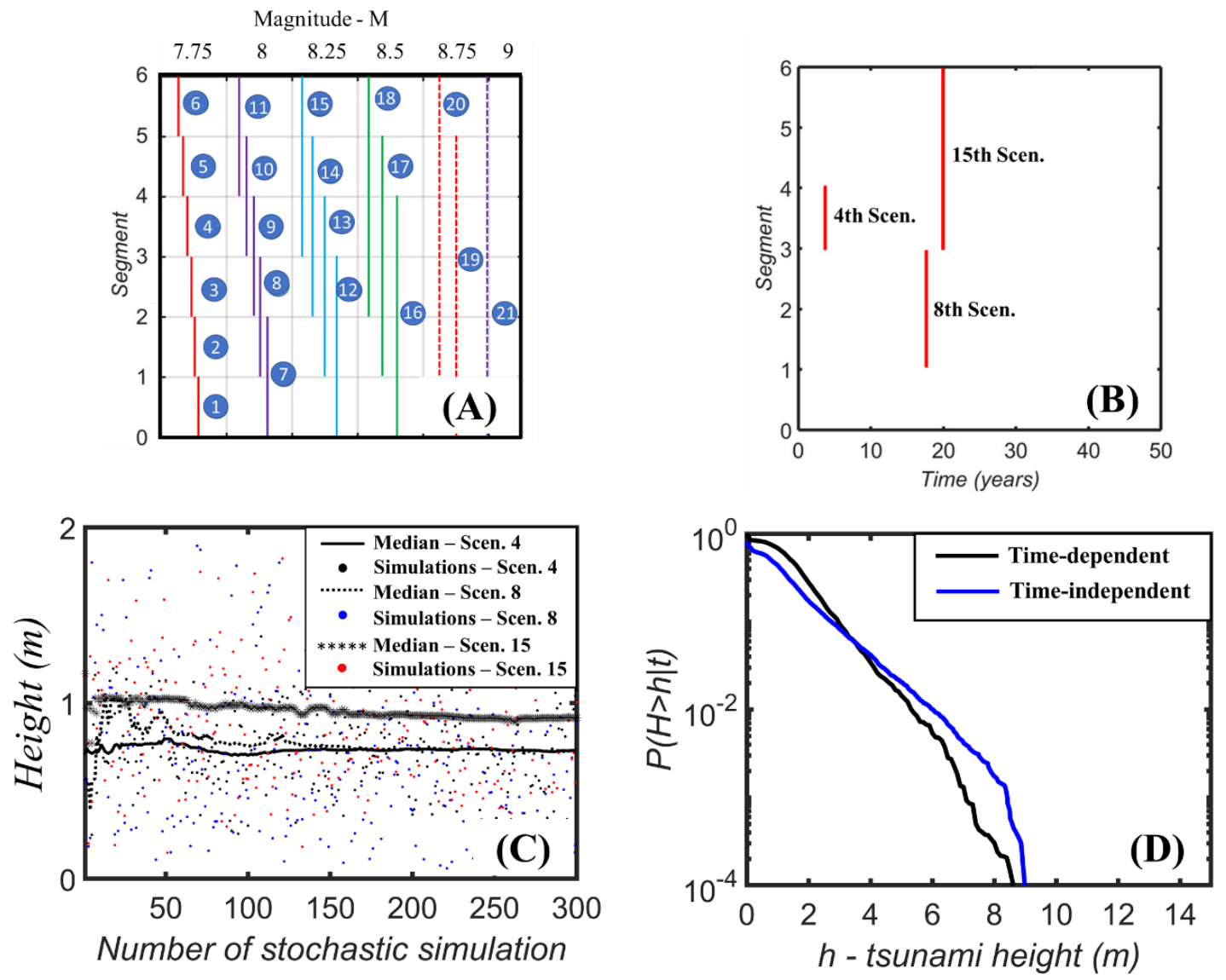

730 Figure 14. Development of final hazard curve for the time-dependent model: (A) segmentation of earthquake rupture and tsunami scenarios, (B) illustration of one simulated rupture catalog (number 152) over 50 years, (C) stochastic tsunami height corresponding to the occurred scenarios in the catalog, and (D) final hazard curve. 

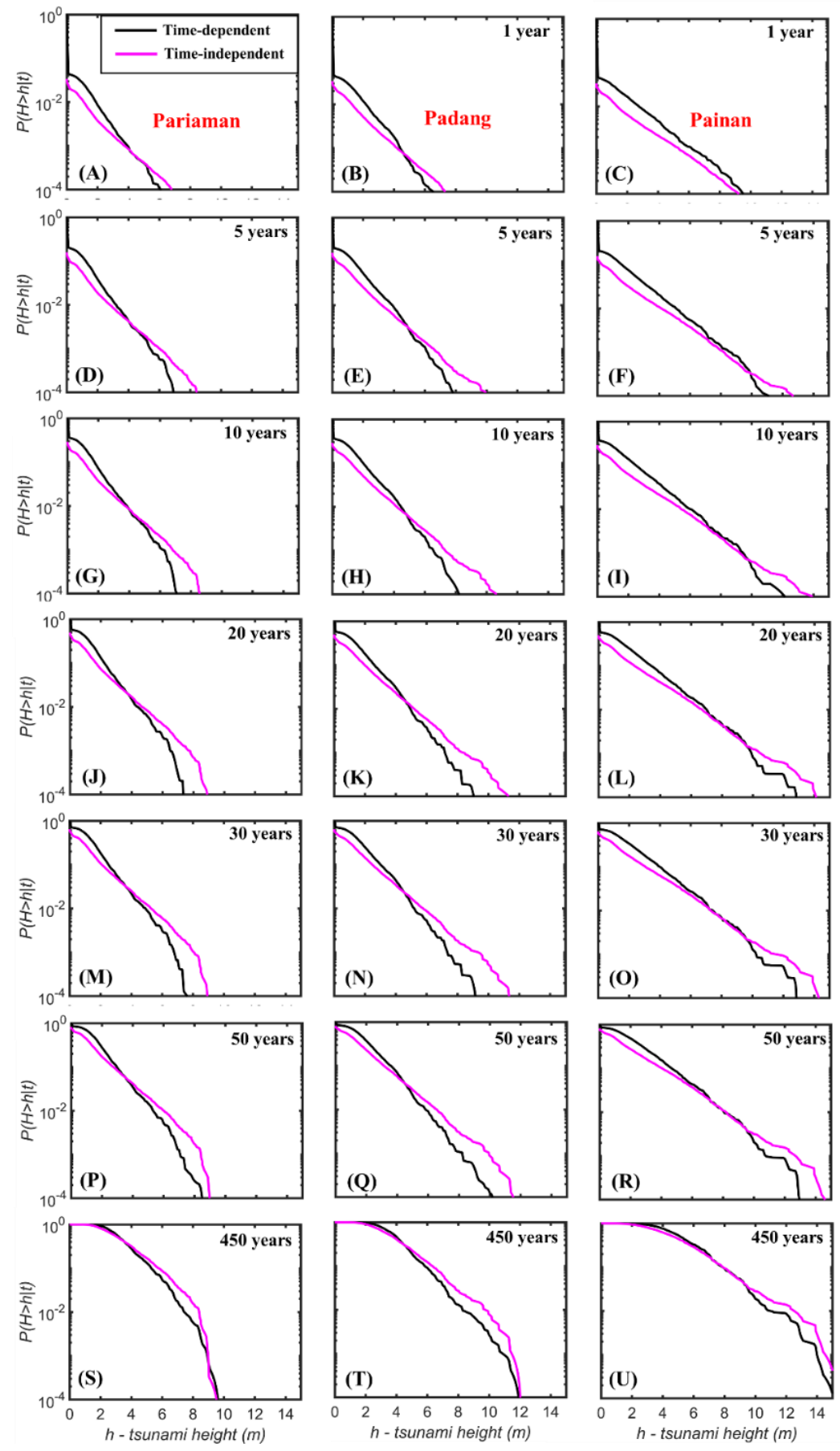

735 Figure 15. Tsunami hazard curves comparison at Pariaman (left panel; P4 in Figure 8), Padang (central panel; P12 in Figure 8), and Painan (right panel; P25 in Figure 8) of time-independent PTHA and time-dependent PTHA approaches for seven considered periods: 1 year (A-C), 5 years (D-F), 10 years (G-I), 20 years (J-L), 30 years (M-O), 50 years (P-R), and 450 years (S-U). 

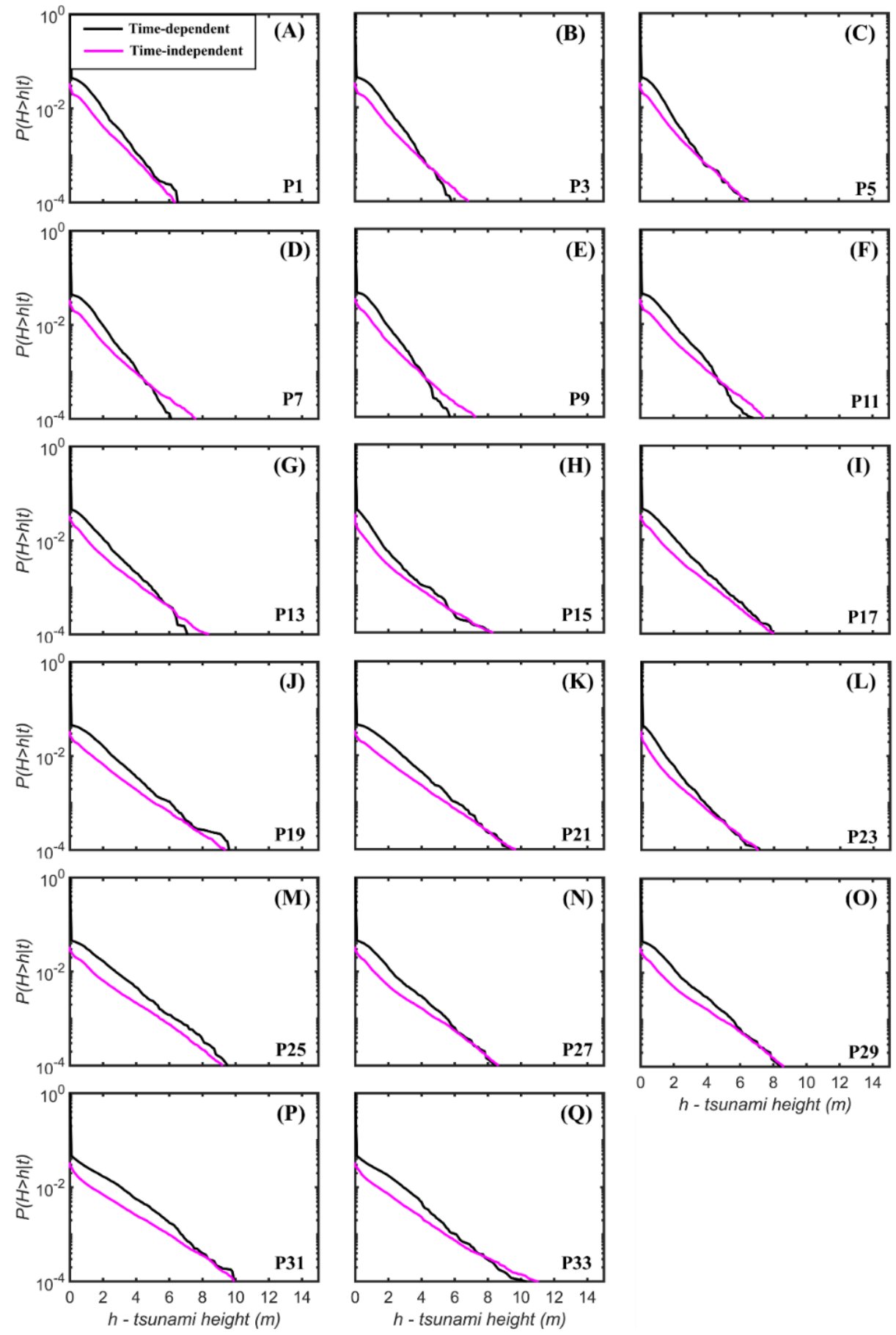

Figure 16. Tsunami hazard curves comparison of 1 year along the coast of western Sumatra (P1 to P33 in Figure 8) of timeindependent PTHA and time-dependent PTHA approaches. 
https://doi.org/10.5194/nhess-2022-59

Preprint. Discussion started: 24 February 2022

(c) Author(s) 2022. CC BY 4.0 License.
Natural Hazards
and Earth System Sciences

Discussions
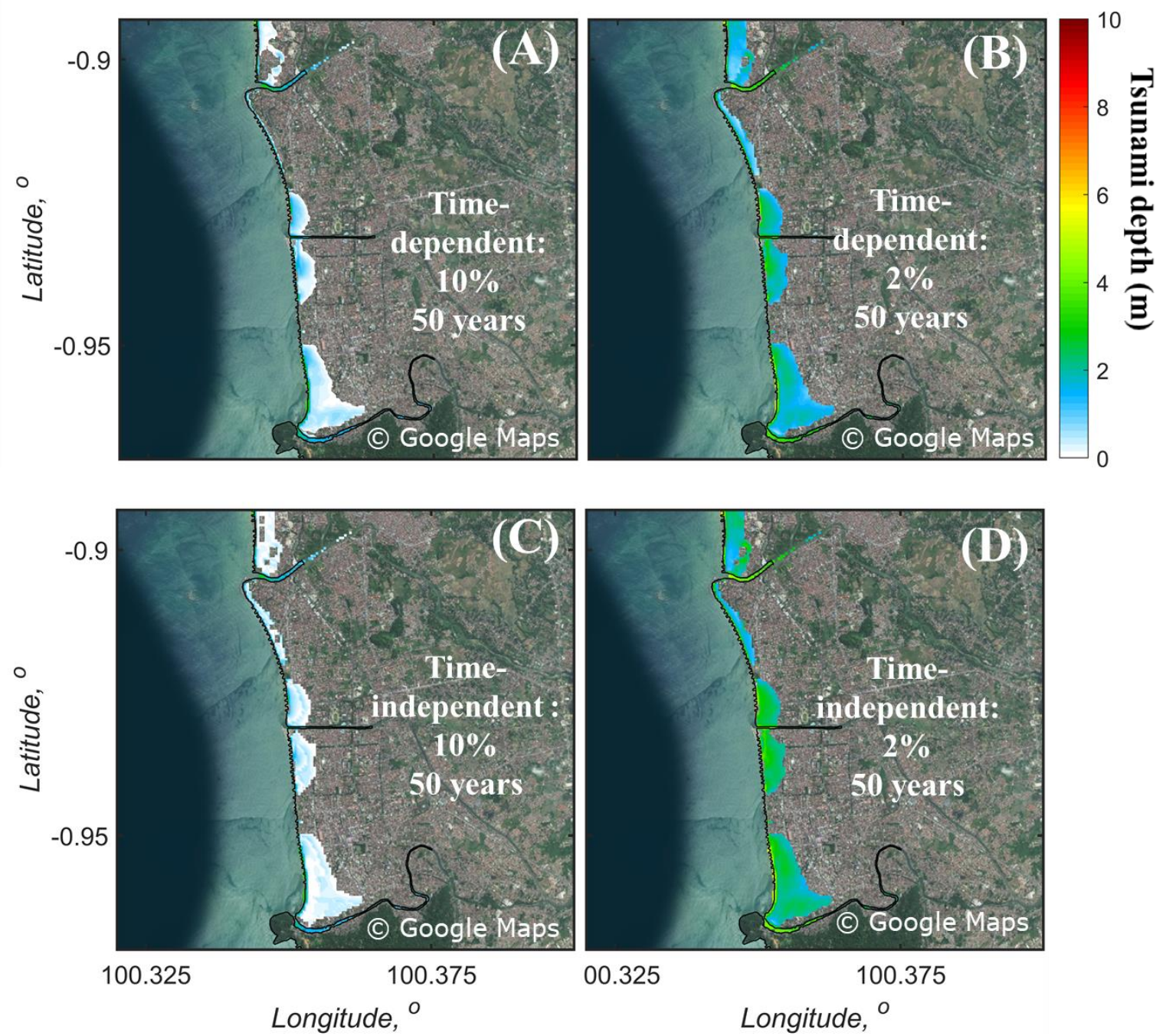

Figure 17.Tsunami hazard maps near Padang (P12 in Figure 8C): (A-B) time-dependent PTHA and (C-D) time-independent

PTHA (Source of base map: (C) Google Maps). 